REVIEW:

\title{
Oleaginous yeasts for biodiesel: Current and future trends in biology and production
}

4 Irnayuli R. Sitepu a,b ${ }^{\text {a, }}$ Luis A. Garay ${ }^{\mathrm{a}}$, Ryan Sestric ${ }^{\mathrm{c}}$, David Levin ${ }^{\mathrm{c}}$, David E. Block ${ }^{\mathrm{d}, \mathrm{e}}$, J. Bruce German ${ }^{\mathrm{a}}$, and Kyria L. Boundy-Mills ${ }^{1 *}$

${ }^{a}$ Department of Food Science and Technology, University of California Davis, One Shields Ave, Davis,

7 California, 95616 USA

$8{ }^{\mathrm{b}}$ Forestry Research and Development Agency (FORDA), the Ministry of Forestry, Jalan Gunung Batu

9 No.5, Bogor 16610, Indonesia

$10{ }^{\mathrm{c}}$ Department of Biosystems Engineering, University of Manitoba, Winnipeg, MB R3T 2N2, Canada

11 Department of Viticulture and Enology, University of California Davis, One Shields Ave, Davis,

12 California, 95616 USA

13 'Department of Chemical Engineering and Materials Science, University of California Davis, One Shields

14 Ave, Davis, California, 95616 USA

$15 *$ Corresponding author. Tel. +1(530)754-5575, FAX +1(530)752-4759. Email address:

16 〈klbmills@ucdavis.edu>

\section{ABSTRACT}

Production of biodiesel from edible plant oils is quickly expanding worldwide to fill a need for renewable, environmentally-friendly liquid transportation fuels. Due to concerns over use of edible commodities for fuels, production of biodiesel from non-edible oils including microbial oils is being developed. Microalgae biodiesel is approaching commercial viability, but has some inherent limitations such as requirements for sunlight. While yeast oils have been studied for decades, recent years have seen significant developments including discovery of new oleaginous yeast species and strains, greater understanding of the metabolic pathways that determine oleaginicity, optimization of cultivation processes for conversion of various types of waste plant biomass to oil using oleaginous yeasts, and development of strains with enhanced oil production. This review examines aspects of oleaginous yeasts not covered in depth in other recent reviews. Topics include the history of oleaginous yeast research, especially advances in the early $20^{\text {th }}$ century; the phylogenetic diversity of oleaginous species, beyond the few species commonly studied; and physiological characteristics that should be considered when choosing yeast species and strains to be utilized for conversion of a given type of plant biomass to oleochemicals. Standardized terms are proposed for units that describe yeast cell mass and lipid

34 production.

\section{KEYWORDS}

37 Single cell oil, SCO, Yeast lipids, Biodiesel, Fatty acid composition, Lipid analysis, Strain development,

38 Process development 


\section{CONTENTS}

41 1. Introduction

42 2. History of yeast lipid research

2.1 Early reports of oleaginous yeasts

2.2 History and prospects of oil production using oleaginous yeasts

45 3. Lipid and fatty acid composition of oleaginous yeasts

3.1 Analysis of total lipid content of oleaginous yeasts

3.2 Fatty acid composition of oleaginous yeasts

4. Strain development

4.1 Comparison of relevant characteristics of oleaginous yeasts

4.2 Examination of enzymatic and genetic factors that contribute to oleaginicity

4.3 Genetic modifications to increase or alter fatty acid production

5. Process development

5.1 Conversion of lignocellulosic hydrolysates to yeast oil

6. Pilot scale and demonstration scale production of yeast lipids

7. Conclusions

\section{Acknowledgments}

60 References 


\section{Introduction}

The purpose of this review is to provide a broad perspective on use of yeast-derived oils for biodiesel production. Topics covered in depth in other publications are introduced to provide perspective, and readers are directed to other publications and reviews for more details. Topics discussed in particular detail in this review include technologies developed in the early research and industrial production of yeast lipids, the taxonomic diversity of oleaginous (high-oil) yeasts, and a comparison of industrially relevant characteristics of a broad range of oleaginous yeast species.

Transportation is the fastest growing energy sector, and the second largest energy consuming sector in the U.S. (28\%) after electric power (40\%) (US Energy Information Administration, 2013). Alternatives to petroleum for liquid transportation fuels are being sought due to global concerns over climate change, energy security, and impending depletion of petroleum reserves. Biodiesel is highly degradable, non-toxic, renewable and sustainable. It has similar combustion properties to petroleum diesel, is a drop-in replacement fuel for existing diesel vehicle and boiler engines without major modifications, and is compatible with current fuel infrastructure. Biodiesel produces very low sulfate emissions, and presents economic potential for rural growers.

So-called "first generation" biodiesel, from edible plant oils, actually predates petroleum diesel. Sir Rudolf Diesel demonstrated his first compression ignition engine at the World Exhibition in Paris in 1898 using peanut oil as fuel (Crew, 1963). Vegetable oils were used to run diesel engines until they were modified to be compatible with petroleum products in the 1920s. Plant oils are comprised primarily of triacylglycerides (TAG). Biodiesel is produced by trans-esterification of TAG using an alcohol, either ethanol or methanol, in the presence of a base, producing fatty acid methyl- or ethyl-esters (Figure 1). Fatty acid composition has been reported to have significant impacts on the performance of biodiesel (Knothe, 2005, 2008, Steen et al. , 2010). Chain length, the degree of unsaturation and branching modify the cetane number, melting point, oxidative stability, kinematic viscosity and heat of combustion, which are relevant properties that a biodiesel must meet in order to comply with official standards, such as ASTM D6751 and EN 14214 (Knothe, 2008). The relationship between the structural features and the chemical specifications are described in Table 1.

Edible plant oils used for biodiesel worldwide are rapeseed (84\%), sunflower (13\%), palm oil (1\%), and soybean and others (2\%) (Atabani et al. , 2012), primarily because these oils have high oleic acid content. This fatty acid provides superior ignition quality, ideal melting point, kinematic viscosity as well as improved oxidative stability (Knothe, 2005, 2008, Steen, Kang, 2010). The fatty acid profile of biodiesel derives from its precursor oil or mixture, if no intermediate winterization (i.e. improvement of cold flow properties) or selective interesterification is applied. For example, when the source is low erucic rapeseed oil (canola), the predominant fatty acids are oleic $(55-65 \%)$ and linoleic $(18-24 \%)$ (Hui, 1996). Two types of sunflower oil are available: high oleic $(60-65 \%)$ or high linoleic $(73-78 \%)$ sunflower oil (Hui, 1996). The former is more expensive, but is preferred for biodiesel purposes due to its higher oleic content. In the case of palm oil, it is common to separate the olein fraction from the stearin fraction via winterization or other crystallization techniques. The olein fraction is preferred for production of biodiesel, due to its high oleic acid content (> 40\%) (Firestone, 2006). Soybean, corn, and high oleic safflower and other types of oils are rarely used for biodiesel production due to high cost and poor oleic 103 acid content. 
Total world biodiesel production is rising sharply to meet demand: production rose from 15,000 barrels per day in 2000 to 289,000 in 2008 (Atabani, Silitonga, 2012), with highest production in the European Union and USA. Plant oil comprises a large portion of the production cost of biodiesel (Miao and $\mathrm{Wu}, 2006)$. The rising cost of edible plant oils, and public debate of the "food vs. fuel" issue, have encouraged development of so-called "second-generation" biodiesel from non-edible plant oils such as jatropha, jojoba, and waste oils such as cooking grease and animal fats. However, these oils may not be sufficiently abundant to meet global needs, and animal fats perform poorly in cold weather as they do not fit the specifications in Table 1.

"Third-generation" biodiesel is under development using oil-accumulating microbes such as microalgae, bacteria, and yeasts and other fungi. Single Cell Oils (SCO), or microbial systems that produce and store oil, have attracted significant research attention recently, primarily in response to the rising price of petroleum. Oleaginous microbes can convert substrates such as carbon dioxide, sugars, and organic acids to SCO. While some species produce intracellular neutral lipid continuously, most cell types require stressors like nutrient deprivation to stimulate lipid synthesis. Once the cells produce the lipid, they are harvested and the cells are lysed by solvent, mechanical, enzymatic, or other means, releasing the lipid. The lipid is then separated from the cell fraction, and the neutral lipid undergoes chemical refining to produce an ester or other target molecule, by releasing the glycerol from the individual fatty acids. Typically, this is done by acid or base hydrolysis in the presence of an alcohol. While the methodology has been established, the current barrier in SCO production is developing a robust system that is cost competitive with petroleum-based fuels. This can be achieved by development of strains able to convert low cost substrates, grow quickly to high density, and produce larger quantities of neutral lipid, and development of improved harvesting and dewatering technologies.

Microbial oils do have some inherent advantages over plant oils: microbial biodiesel could be produced year-round (given available feedstock), on land unsuitable for agriculture, with production rates up to 100X that of plant oils in liters/hectare/year (Atabani, Silitonga, 2012). Of the 33,000 known species of algae (Brodie et al. , 2007, Guiry and Cunningham, 1984), at least forty are considered oleaginous (Griffiths and Harrison, 2009), i.e. they have been demonstrated to accumulate over 20\% lipid by dry weight (Ratledge, 1979). Doubling times vary considerably, depending on species and growth conditions, ranging from hours to days (Sheehan, 1998). Oil and hydrocarbon content of oleaginous species can range from $20-60 \%$, and up to $80 \%$ for exceptional genera such as Nannochloropsis, Schizochytrium and Botryococcus (Chisti, 2007).

High-value nutritional oils including docosahexaenoic acid (DHA), eicosapentaenoic acid (EPA), gamma linolenic acid (GLA) and arachidonic acid (ARA) are currently produced commercially utilizing different types of microorganisms. This demonstrates that SCO production is not limited to one clade of microorganisms (Cohen and Ratledge, 2005). For example, filamentous fungi have been used for the commercial production of GLA (Mucor circinelloides) and ARA (Mortierella alpina). Ulkenia sp, a marine microalga is also being used commercially for producing DHA-rich oil (Cohen and Ratledge, 2005). The microalga Nannochloropsis is used to commercially produce EPA (Green et al. , 2012, Weissman et al. , 2012). Furthermore, certain Thraustochytrids, comprising species such as Schizochytrium sp., are also being used to source commercial oils rich in DHA. These organisms in the past were originally classified as fungi because of their heterotrophic nature and superficial resemblance to chytrids, but recently they were reclassified as microalgae-like microorganisms by molecular biology 
techniques. Dinoflagellates such as Crypthecodinium cohnii, are also being used commercially to source high DHA oil (Cohen and Ratledge, 2005, Eckelberry et al. , 2010, Ratledge, 1993).

Commercial production of these oils demonstrates that large-scale production of microbial oil is feasible, given an appropriate process and market. However, these examples are high value specialty chemicals. Further strain and process improvements are needed to make production of microbial commodity oleochemicals such as biodiesel economically feasible.

Estimating the cost of single cell oils has been difficult, and biodiesel cost projections have ranged from $\$ 1$ to $\$ 80$ per gallon (Davis et al. , 2011). The economics of algal SCO has been examined more thoroughly than other cell types, and provides a template for other SCO biofuels. Algae, unlike yeast or bacterial models, have different culturing methodologies that add additional dimensions to the economic analysis. Algae are cultured by photoautrophic, heterotrophic, or mixotrophic metabolism. Cultivation options include outdoor raceway ponds, enclosed photobioreactors, and enclosed dark fermentors. While multiple culturing styles and reactor options allow for more opportunity and combinations, the complexity of the economic evaluation increases. Several parameters such as algal biomass characteristics, reactor supply costs, labor, days of operation, substrate cost, dewatering, and extraction methods must be considered in order to provide the data inputs associated with the oil cost.

In a techno-economic analysis, Davis et al. 2011 (Davis, Aden, 2011) compared photoautotrophic algal growth in an open raceway pond to an enclosed photobioreactor (PBR). Several parameters affecting the production costs of algal culturing were standardized, such as production for 330 days per year, fixed $\mathrm{CO}_{2}$ costs from flue gas, autoflocculation coupled with chitosan addition, cheap local water costs, and butanol lipid extraction. All values were derived from actual industrial costs. Algal biomass productivities were set at $0.5 \mathrm{~g} \mathrm{~L}^{-1}$ and $4.0 \mathrm{~g} \mathrm{~L}^{-1}$ for raceway ponds and PBRs respectively, assuming that enclosed reactors produce more biomass. From this analysis, the cost of the TAG was $\$ 8.52$ and $\$ 18.10$ per gallon ( $\$ 2.24$ and $\$ 4.76$ per liter) for open pond and closed reactor cultures. Converting the TAG to diesel-like molecules by hydrotreating the lipid added additional costs, making the biodiesel \$9.84 and $\$ 20.53$ per gallon ( $\$ 2.59$ and $\$ 5.40$ per liter). The outdoor open ponds were more cost effective for photoautotrophic growth using $\mathrm{CO}_{2}$.

Ratledge and Cohen (Ratledge and Cohen, 2008) examined the prospects of both yeast and algal oils. They calculated that the price of yeast SCO, based on existing technologies in 2008, would be US\$ 3000 per tonne (excluding the cost of the feedstock), which was twice that of comparable plant commodity oils used for biodiesel. Thus they concluded that yeast oils will not become economically viable until petroleum and plant oil prices rise further. A more recent estimate of the cost of production of SCO in China from lignocellulosic biomass is 7500 RMB (US\$ 1230) per ton, including the cost of lignocellulosic biomass (Huang et al. , 2013a).

Improvements in the SCO production process could result in an economically viable process. These include reduction of feedstock transport, pretreatment and hydrolysis costs; reduction of aeration and $\mathrm{pH}$ control costs; reduction of contamination potential; year-round production; improved utilization of the carbohydrates in lignocellulosic hydrolysates; faster microbial growth to a higher cell density; higher oil accumulation; improved oil harvesting technologies; conversion of residual yeast cell mass into valuable coproducts; and reduced waste disposal costs.

In order for single cell derived biodiesel to become economically viable, the biodiesel must be viewed as one member of a portfolio of high value coproducts. Prevailing models instead view SCO as 
one valorized product, with the rest of the yeast cell mass considered as simply a waste product, or lowprofit product streams such as animal feed or fertilizer. For comparison, current business models in oilseed processing have met significant success in generating multiple coproducts, with a significant proportion of revenue coming from coproducts such as texturized protein, lecithin and sterols.

Microalgae biodiesel and other oleochemicals are under commercial development by many companies including Pond Biofuels, Algae.Tec, Algenol Biofuels, Aurora Algae, BioProcess Algae, Cellana, LiveFuels, Imperium Renewables, PetroSun, Sapphire Energy, Solazyme, and Solix. Most microalgae companies cultivate algae photosynthetically to limit the cost of input materials. However, some companies have found that heterotrophic growth conditions are significantly more productive, producing higher oil content and higher cell density in a shorter time frame, compensating for the added cost of providing a carbon source. For example, Solazyme's heterotrophic algal oil production system can reportedly produce thousands of gallons of oil per month, higher productivity than photosynthetic systems (Solazyme, 2013). Microalgae are strong oil producers, but require significant land if grown photosynthetically (Meng et al. , 2009), are subject to daily and seasonal variation due to weather, are prone to contamination by bacteria and predatory protozoa, may require low density cultures for optimal production, and require large volumes of cultivation and process water (Chisti, 2007).

Other oleaginous microbes including bacteria, yeasts and filamentous fungi have been considered for use in production of oleochemicals including biodiesel. More information about oleaginous bacteria and filamentous fungi can be found in reviews (Li et al., 2008, Meng, Yang, 2009, Shi et al., 2011). Yeasts, or single-celled fungi, are the focus of this review. For decades, oleaginous yeasts have been studied as a microbial source of oil for oleochemicals including fuels, platform chemicals, and food and feed ingredients (Woodbine, 1959). Like heterotrophically-grown algae, yeasts can be grown under tightly controlled conditions in bioreactors, they grow quickly to high density, and they can accumulate up to $70 \%$ oil by dry weight. Oil can be extracted using similar methods used for algae, and yeasts can be genetically modified to improve production. Advantages of yeasts over algae include potentially faster growth, higher density growth, less susceptibility to viral infection, and ability to control bacterial contamination using low $\mathrm{pH}$ growth conditions. California-based microbial oil company Solazyme has applied for several patents on use of yeast oil for fuels, chemicals and food ingredients (Franklin et al. , 2011a, Franklin et al. , 2011b, Trimbur et al. , 2012a, b), evidence of strong industrial interest in oleaginous yeast.

\section{History of yeast lipid research}

Yeasts are defined as "fungi that asexually reproduce by budding or fission, which results in growth that is comprised mainly of single cells" (Kurtzman et al. , 2011b). This definition recognizes that many yeast species are capable of multicellular, mycelial growth, a characteristic that is rarely mentioned in discussions of oleaginous yeasts (Wassef, 1977). They are taxonomically diverse, belonging to two of the seven fungal phyla, Ascomycota and Basidiomycota. There are over 1600 known species of yeasts, a figure that has more than doubled in the last 12 years (Kurtzman et al. , 2011a, Kurtzman and Fell, 2000). This boom in novel yeast species descriptions has allowed discoveries in other fields such as identification and characterization of pathogenic (Cooper, 2011) or food spoilage yeasts (Fleet, 2011), profiling food and beverage fermentations (Bokulich et al. , 2011, Bokulich, 2012, Bokulich et al. , 2012a, 
Bokulich et al. , 2012b, Bokulich and Mills, 2013), and biotechnology applications (Johnson and Echevarri-Erasun, 2011).

Yeasts have been harnessed for biotechnological applications for thousands of years: the yeast Saccharomyces cerevisiae, used for producing beer, bread, wine and other delightful products, has been called the "first domesticated organism" (Vaughan-Martini and Martini, 1995). Yeasts are used in biotechnology applications because they are genetically tractable, easy to cultivate, have a long history of safe use, and relatively few yeast species are known to be pathogenic to humans, plants or animals. Yeasts including Saccharomyces cerevisiae and Pichia pastoris are used as hosts for production of recombinant proteins in pharmaceutical and other industries. Yeasts are also particularly useful for renewable, sustainable production of biodegradable oils for food, feed, fuels and chemicals. Many discoveries were made during the early decades of yeast oil work that have propelled modern studies, including discovery of high-oil species, culture conditions that promote lipid accumulation, conversion of waste products to yeast oil, and pilot and commercial scale production of marketable products.

\subsection{Early reports of oleaginous yeasts}

The lipids of yeasts have been a subject of study since 1878 (Nageli and Loew, 1878), when the fatty acid composition of Saccharomyces cerevisiae was reported. In 1899, Lindner observed that Torula pulcherrima (now called Metschnikowia pulcherrima) could accumulate high levels of intracellular fat (Woodbine, 1959). Research on Oidium lactis (now called Galactomyces candidus) including fatty acid identification and quantification was performed by Kaufmann and Schmidt in Germany in the late 1930s (Piskur, 1939). Lindner observed formation of fat globules in Torula pulcherrima (now called Metschnikowia pulcherrima) in 1889 (Woodbine, 1959). Researchers at German research institutions including Mannheim-Waldhof intensively studied fat-forming yeasts, particularly during World Wars I and II. Early discoveries also included identification of high-oil producing yeast species such as Lipomyces lipofera (Nilsson et al. , 1943), Lipomyces starkeyi (Lodder and Kreger-van Rij, 1952, Starkey, 1946), and Rhodotorula glutinis (Enebo et al. , 1944).

A 1946 report from the British Intelligence (Stanier, 1946) based on interviews of German scientists describes work done in Germany during World War II on a variety of microbial products including fats for food, feed and fuel uses. Researchers at the Mikrobiologisches Institut at Göttingen performed a systematic investigation of numerous microbes, and discovered that certain strains of yeasts accumulated high levels of intracellular lipids. Strains of Nectaromyces reukaufii (now called Metschnikowia gruessii) had production advantages including ability to grow in lab medium containing waste products as growth nutrients (whey and bran), fast growth, and early lipid accumulation (34\% oil by dry weight at four days growth).

\subsection{History and prospects of oil production using oleaginous yeasts}

Development of high-lipid yeasts as a nutritional supplement and food ingredient in the first half of the $20^{\text {th }}$ century resulted in many technological breakthroughs. Some highlights of the history of nutritional yeast lipids are presented as these advances made current development of yeast lipid-based

268 oleochemicals possible. Curious readers are encouraged to read the cited publications for more details. 
Yeasts, particularly brewer's yeast (Saccharomyces cerevisiae) and Torula yeast (Candida utilis), have been food ingredients for over a century. Thousands of tons of Torula yeast were consumed during World Wars I and II by soldiers and civilians in Germany as a meat substitute or meat extender (Goldberg, 1985). Lipid bodies were observed in Torula yeast grown for protein production, which led to further examination and commercial development of yeasts as a source of nutritional oils, especially during times

During World War I, Lindner performed pilot scale studies in Germany growing Endomycopsis vernalis (now called Guehomyces pullulans) on a solid surface such as straw or wood chips (Woodbine, 1959). This species was also grown on sulphite liquor, accumulating up to 45 percent fat (Lindner, 1922). Lindner observed in 1915 that protein production predominated in medium containing high assimilable nitrogenous compounds, and lipid production predominated under lower nitrogen conditions (Lundin, 1950). Lindner used the German term "Fetthefe" (yeast fat) to describe nutritional oil produced in small scale using the yeast Endomyces/Endomycopsis vernalis (now called Guehomyces pullulans), and proposed using abandoned breweries to produce yeast fat (Lindner, 1922). Two factories were established in Marburg and Danzig for industrial fat production using Endomycopsis vernalis (Lundin, 1950). This high-fat paste "was used in the baking of bread, in dough instead of fat, for spreading on bread instead of butter, and so on". Sulfite waste liquor from the cellulose industry was used as the carbohydrate source. However, these factories ceased production after a short time due to inefficient production methods. Aeration was identified as a limiting factor. To achieve sufficient aeration, the microbes were cultivated in shallow trays or on suspended fabric belts refreshed with liquid media, which resulted in high-lipid yeast cell mass, but problems included low yield, frequent contamination, large space requirements, and high cost.

Growth conditions, particularly aeration, were explored that would improve both yeast cell mass and lipid production, resulting in pilot and commercial scale production of yeast lipids. In the last years of World War II, a factory was built near Munich for oil production using Oospora lactis (now called Galactomyces candidus) grown under deep liquid conditions on whey and hydrolysates of straw and sawdust (Lundin, 1950). Critical factors for high yield in deep culture were identified by Lindner and colleagues, and included abundant supply of a carbon source, abundant oxygen supplied thorough aeration, and use of a young, actively dividing inoculum (Hesse, 1949, Woodbine, 1959). Hesse (Hesse, 1949) described in detail a commercial process developed by Schmidt and used to produce a spray-dried yeast product from Torulopsis utilis (now called Cyberlindnera jadinii), which was grown in 8m diameter, $6 \mathrm{~m}$ height fermentation vats in a fed batch manner on beech liquor emulsion, pine liquor emulsion, and wood sugar emulsion. Other early pilot scale studies performed in the 1940s included 10,000 liter-scale production of a high-fat (25.3\%) nutritional yeast paste having a "pleasant, peanut-like taste" using the species Candida reukaufii (anamorph of Metschnikowia reukaufii) (described in (Koch, 1949, Koch et al. , 1949, Woodbine, 1959). Lundin proposed incorporating dried, ground yeast cell mass in foods rather than extracted oil, as the yeast also provides high concentrations of protein, thiamin, riboflavin and niacin. Despite promising results, planned trials of large-scale conversion of bran extract to oil using oleaginous yeast Metschnikowia gruessii were cancelled when Germany was defeated (Stanier, 1946).

Lindner proposed three mechanisms of isolating oil from microrganisms: grinding with sand followed by ether extraction, treatment with dilute hydrochloric acid, or autolysis at $50^{\circ} \mathrm{C}$ (Hesse, 1949). The latter two would result in edible fat plus a high-protein material that could also be utilized as a food ingredient. Oil from Rhodotorula glutinis was described as similar to olive oil (Hesse, 1949), though it 
was observed that microbe fats tend to become rancid relatively quickly, which is characteristic of oils high in free fatty acids. The free acid content of microbe oils was indeed found to be rather high, but varied depending on the growth conditions (Damm, 1943, Reichel, 1940).

Work on oleaginous yeasts was also performed in other countries. Workers in Sweden developed methods to cultivate Rhodotorula glutinis in deep cultures under aeration, with accumulation of $35 \%$ lipid (Nilsson, Enebo, 1943). However, this species produced undesirable mucous substances as well. Properties of eleven other species in this genus were compared, and Rhodotorula gracilis (now called Rhodosporodium toruloides) was superior in growth rate, fat-producing capacity and filterability (Enebo et al. , 1946, Enebo, Elander, 1944). This was an early example of screening wild yeast strains selected based on phylogenetic relation to a promising species, a strategy that continues to be fruitful.

\section{Lipid content and fatty acid composition of oleaginous yeasts}

As stated above, in this review, we use the standard convention for classifying a yeast as "oleaginous", which is the ability to accumulate at least $20 \%$ oil as a percentage of cell dry weight (Ratledge, 1979).

Lipids are structurally diverse biological molecules that are relatively insoluble in water and soluble in organic solvents. They include two basic categories: (1) molecules derived from isoprene units, such as steroids and carotenoids, and (2) fatty acids and their long-chain relatives such as fatty alcohols, alkanes and alkenes. Commonly used fats and oils from plants and animals belong to the latter category.

Yeasts contain various types of lipids (Blagović et al. , 2001, Lösel, 1988, Rattray, 1988, Schweizer, 2004), including triacylglycerols, diacylglycerols, monoacylgycerols, fatty acids, steryl esters, free sterols, glycerophospholipids, cardiolipins, sphingolipids, glycolipids, hydrocarbons (comprising straight chain hydrocarbons, squalene and carotenoids), long chain alcohols, waxes, polyprenols, isoprenoid quinones, and others. In the plasma membrane four types of lipids can be easily distinguished: glycerophospholipids, sphingolipids, steryl esters (mainly from ergosterol), and mono and diacylglycerols. In Saccharomyces cerevisiae, the most abundant glycerophospholipids are phosphatidylcholine (PC), phosphatidylethanolamine (PE), phosphatidylserine (PS) and phosphatidylinositol (PI) (Schweizer, 2004). Lipid composition in the plasma membrane varies amongst strains, even closely related strains (Henderson et al. , 2012, Henderson et al. , 2011), and is a function of temperature (Henderson et al. , 2013b). Lipid composition is highly correlated with cell function such as ethanol tolerance (Henderson et al. , 2013a). Sphingolipids in yeast include sphinganine and its derivatives, phytosphingosine, sphingomyelin Ceramide A-D, and 3 complex sphingolipids (Dickson and Lester, 2002, Rattray, 1988). Lipids such as oxysterols have been found in the mitochondrial membrane, playing a role in apoptosis, cellular aging and sphingolipid metabolism (Schweizer, 2004) Cardiolipins have also been found in yeast mitochondrial membranes. They are required for cytochrome oxidase activity, as well as mitochondrial protein import (Schweizer, 2004).

Glycolipids of the form of sophorosides of hydroxy fatty acids are secreted by certain types of yeasts, such as Candida bombicola and Rhodotorula bogoriensis (Nuñez et al. , 2004, Rattray, 1988, Stodola et al. , 1967, Van Bogaert et al. , 2011). Polyprenols including dolichols are found as phosphate esters in the cell wall, playing a role in transferring monosaccharide and oligosaccharide units during $\mathrm{N}$-glycosylation of cell wall glycoproteins (Rattray, 1988). Some yeast species may accumulate only triacylglycerols in lipid bodies, while others may accumulate only sterol esters, and still others, like Saccharomyces cerevisiae can accumulate both (Czabany et al. , 2008, Murphy, 2012). Accumulation of hydrocarbons in 
lipid-rich cytoplasmic granules has been reported for Candida tropicalis when grown on n-alkane rich media (Rattray, 1988). Additionally, accumulation of squalene in membranes of yeast cells grown anaerobically has also been reported (Spanova et al. , 2012), The classes of lipids present, and the proportions of membrane vs. storage lipids, vary with the species and strain, culture conditions and the growth stage of the culture.

While oleaginicity is defined based on the percent dry weight, this is not the only, or always the best, unit used to report lipid productivity. Other units seen in the literature describe the final mass of lipid per liter culture, production of lipid per day, proportion of input carbon converted to lipid, and others. Examples of measures reported in the literature are listed in Table 2. It is important to define the units being used, as the same terms can have different meanings in different publications. For example, "lipid yield" is defined more than one way (compare (Gill et al. , 1977, Huang et al. , 2012b). In general, productivity ratios may include in the numerator diverse units of dry cell mass, wet cell mass (typically described as cell pellet) total lipid mass, or specific fatty acid or even secreted lipid mass, while in the denominator some authors use different units for culture volume, carbon source mass (such as carbohydrates, alcohols, alkanes or other sources of carbon), units of time (i. e. per day or per hour). A diverse array of combinations can be created from these options, depending on the desired purpose and analytical capabilities. For example, some researchers report the ratio of product relative to input carbohydrate consumed, which requires determination of the residual carbohydrate in the spent media.

If the goal is to determine mass balances, process design and flow rates, ratios such as dry cell mass per volumetric unit culture and/or unit time are useful. When the goal is to establish the biochemical transformation of the substrate by a given strain, then ratios such as dry cell unit mass per unit mass of substrate (i. e. carbohydrate, alcohol, alkane, etc.) are used, commonly referred to as cell mass yield for yeasts, biomass yield for algae, or yield coefficient for microbes in general. Furthermore, if the purpose is to determine the lipid extraction yield, then ratios such as total lipid mass per dry cell mass unit or total lipid mass per volume/mass unit culture per hour may be used. In vegetable oil production, it is also common to use similar ratios. However, instead of referring to volumes and/or mass of substrates or culture, the ratios typically refer to the initial amount of seed (expressed in mass units) or crop unit area. This is useful because it helps establish the bioconversion performance of the process. It provides insight on what it takes to obtain a unit amount of oil or lipid from a given amount of seed or cropland.

From an ecological point of view, many oleaginous species occupy relatively dry, nutrient-poor habitats such as plant surfaces (Kurtzman, Fell, 2011a). Storage lipids, being hydrophobic, would presumably be more resilient to desiccating conditions than storage carbohydrates. As discussed in Section 4.1, ability to utilize a variety of carbon sources would be an advantage in these environments. Most oleaginous yeast species can utilize a broad variety of carbon sources. A notable exception is Yarrowia lipolytica, which is relatively finicky, with wild strains unable to consume most sugars found in lignocellulosic hydrolysates except glucose. Most oleaginous yeast species cannot ferment carbohydrates, a skill that is advantageous in aqueous, sugar-rich environments. Most oleaginous yeast species are obligate aerobes. This combination of traits allows these yeasts to survive the famine for long periods in dry, nutrient-poor niches, and feast and store reserves when an unpredictable range of carbon sources such as lignocellulosic breakdown products becomes available. Thus oleaginous yeasts are particularly adept at assimilating and storing carbon in a form that helps assure survival through the next famine.

Oleaginous yeasts store lipids mainly in the form of triacylglycerols (TAG) in intracellular lipid bodies. The primary component fatty acids in these TAG have been under investigation for over 100 
years: in 1878, ten years before the first yeast species was named, brewing yeast (Saccharomyces cerevisiae) was reported to contain oleic, stearic and palmitic acid (Nageli and Loew, 1878). These three fatty acids, along with linoleic, linolenic and palmitoleic acids, are the major fatty acids of most yeast species analyzed (for example, (Henderson, Lozada-Contreras, 2011, Kaneko et al. , 1976, Sitepu et al. , 2013, Viljoen et al. , 1986, Woodbine, 1959). The dominant fatty acids in yeasts storage lipids are thus similar to those found in plant-derived oils, making them an appropriate substitute for vegetable oils for biodiesel and other oleochemicals.

As discussed in Section 3.3, fatty acid methyl ester (FAME) analysis has been used to characterize hundreds of yeast species because FAME profiles were used to identify yeast species (Augustyn et al. , 1992, Botha and Kock, 1993, Jeffery et al., 1997, Van Rensburg et al. , 1995, Viljoen, Kock, 1986) before ribosomal DNA sequencing gained prominence. However, the number of described yeast species has more than doubled since this method was commonly used, thus the reference databases no longer contain a large proportion of known yeast species. Growth conditions must be tightly controlled when using this method for species identification, as the relative abundance of fatty acids for a given strain varies under different growth conditions, such as carbon source (Easterling et al. , 2009), nitrogen depletion and age of culture (Sitepu, Sestric, 2013). Furthermore, the fatty acid total content and relative abundance varies among strains of the same species (Kaneko, Hosohara, 1976, Leiva-Candia et al. , 2014, Sitepu et al. , 2012, Sitepu, Sestric, 2013, Viljoen, Kock, 1986).

A recurring theme of this review is that discoveries and methods of the past are re-surfacing. For example, the methods used to prepare FAME for yeast species identification (Augustyn and Kick, 1989, Augustyn, Kock, 1992) involve direct methanolysis of dried yeast cells. A similar method has been used recently to prepare FAME from oleaginous yeast cells for evaluation of biodiesel production and fuel properties (Liu and Zhao, 2007).

\subsection{Discovery of oleaginous yeast species and strains}

While most publications cite a small set of oleaginous yeast species and strains, there are actually over 70 oleaginous yeast species known. Yeast strains determined to be oleaginous (having at least 20\% oil by dry weight) are listed in Table 3, along with an early literature reference of high lipid content. It must be emphasized that the cited oil content is just one recorded value for this species. Other strains of the species, or the same strain grown under different conditions, may contain more or less lipids.

For many decades, the majority of studies of oleaginous yeasts have dealt with a few species, namely Yarrowia lipolytica, Lipomyces species, Rhodotorula glutinis, $R$. graminis, Cryptococcus curvatus, $C$. albidus, and Rhodosporidium toruloides. As seen by the long list of species in Table 3, there are dozens of additional oleaginous species that have been discovered over the years, but have been less intensely studied. Consideration of a broader range of oleaginous yeast species and strains allows selection of yeasts with hydrolysate-specific baseline properties such as carbohydrate utilization, osmotolerance, tolerance of low $\mathrm{pH}$, and inhibitor tolerance.

Most studies have been conducted to search for oleaginous species using sets of randomly selected strains. In a 1988 comprehensive review summarizing dozens of publications on lipid analysis covering 480 yeast strains, 46 strains belonging to 14 species were reported to be oleaginous (Rattray, 1988), producing up to $71 \%$ oil (w/w). In 1976, Kaneko et al. (Kaneko, Hosohara, 1976) determined the lipid content and composition of 30 yeast species, and found that two of them (two Lipomyces species) were 
oleaginous. A 2011 survey of 889 unidentified soil and palm oil waste fungi (Kitcha and Cheirsilp, 2011) resulted in discovery of 23 oleaginous fungi, and introduced one new oleaginous yeast species, Kodamaea ohmeri. These three examples using randomly selected microbes resulted in an oleaginous yeast discovery rate of $3-10 \%$.

Five examples of targeted screening demonstrated that selection of strains based on physiological properties or phylogenetic placement have been more fruitful. (1) Selective cultivation of environmental microbes that could continue growing for several generations in carbon-free medium using their own stored lipids as the sole carbon source resulted in the discovery that Cryptococcus adeliensis is oleaginous (Li et al. , 2012). (2) Enrichment of soil yeasts able to grow on glycerol as a sole carbon source resulted in enrichment for oleaginous yeasts, with 13 oleaginous strains out of 40 yeasts examined (Pan et al. , 2009). (3) Selective cultivation of soil yeasts able to grow on nitrogen-poor medium yielded a high proportion of oleaginous yeasts: 48 out of 170 strains screened (Kraisintu et al. , 2010). (4) Researchers at ATCC recently checked the species identity of yeasts deposited in their patent repository for applications related to oleaginicity (Gujjari et al. , 2011). While some belonged to known oleaginous yeast species, others belonged to new oleaginous species that they named Trichosporon cacaoliposimilis and T. oleaginosus. (5) Comparison of the lipid accumulation by yeasts phylogenetically similar to known oleaginous species Lipomyces starkeyi resulted in discovery of oleaginous species L. doorenjongii and L. kockii (Oguri et al. , 456 2012).

A targeted strain screening strategy was recently quite successful in identifying new oleaginous yeast species and strains. The study was made possible through access to a highly diverse and well characterized culture collection, the Phaff Yeast Culture Collection at the University of California Davis (http://phaffcollection.ucdavis.edu). Yeasts belonged to known oleaginous species, their taxonomic relatives, or were buoyant: strains that floated when cell mass was placed in $20 \%$ glycerol for cryopreservation. These properties proved to be strong indicators of oleaginicity: eleven out of fifteen species screened were oleaginous, with five of them being new oleaginous species (Sitepu, Ignatia, 2012)). This is a significantly higher discovery rate than the $3-10 \%$ hit rate of randomly selected strains described above. It is important to note that widely varying lipid content was seen among independent isolates of the same species: four independent isolates of Rhodosporidium diobovatum had lipid contents ranging from $21 \pm 5 \%$ to $41 \pm 2 \%$ (w/w). In another recently published study, also targeting relatives of known oleaginous species or buoyant yeasts, of 69 strains analyzed, 43 produced greater than $20 \%$ oil (w/w) based on gravimetric analysis. This study resulted in discovery of an additional 12 new oleaginous species (Sitepu, Sestric, 2013). Between these two papers, seventeen new oleaginous species were reported:

- Kurtzmaniella cleridarum UCDFST 76-729.2

- Myxozyma melibiosi UCDFST 52-87

- Rhodosporidium paludigenum UCDFST 09-163

- Rhodotorula colostri UCDFST 67-113

- Rhodosporidium babjevae UCDFST 05-775, 04-877, 68-916.1

- Rhodosporidium diobovatum UCDFST 04-830,UCDFST 08-225 and UCDFST 67-405

- Rhodosporidium fluviale UCDFST 81-485.4

- Cryptococcus terreus UCDFST 61-443

- Cryptococcus wieringae UCDFST 05-554

- Cryptococcus oierensis UCDFST 05-864

- Hannaella aff. zeae UCDFST 92-112 
- Tremella encephala UCDFST 68-887.2

- Cryptococcus victoriae UCDFST 10-939

- Cryptococcus aff. taibaiensis UCDFST 73-750,

- Trichosporon guehoae UCDFST 60-59,

- Cryptococcus ramirezgomezianus UCDFST 54-11.224,

- Prototheca aff. zopfii UCDFST 10-495

Sixteen of these are yeasts; Prototheca is a genus of achlorphyllous algae, morphologically similar to yeasts. As detailed in Table 3, these new oleaginous yeast species represent broad taxonomic diversity. They also exhibit diversity of growth characteristics relevant to industrial applications such as utilization of carbon sources, ability to grow without supplemented vitamins, growth temperatures, and fatty acid profiles. These new oleaginous species include three putative undescribed species, new to science, indicated as "aff.", abbreviation of Latin "affinis", meaning "related to" the closest taxonomic relative. Lipid contents range broadly: while Trichosporon brassicae CBS 6382 barely qualifies as oleaginous with a lipid content of 20.34\% (Franklin, Decker, 2011a), Rhodosporidium babjevae UCDFST 05-775, with a lipid content of 65\% (Sitepu, Sestric, 2013), approaches some of the highest yeast lipid contents reported in the literature (Papanikolaou and Aggelis, 2011).

The genus names listed above do not fully convey the taxonomic diversity of these newly identified species. Due to inconsistencies in yeast systematics (currently being resolved, (Hibbett and Taylor, 2013), some genera including Rhodotorula, Cryptococcus and Candida are highly polyphyletic, with species placed taxonomically in multiple families, or even multiple orders. Therefore oleaginous species within the same genus are not necessarily closely related to each other phylogenetically. The six new oleaginous Cryptococcus species listed above are members of three different orders, as listed in Table 3. Of over 100 known species of Cryptococcus, which are spread across five taxonomic orders, sixteen species in three orders have been demonstrated to be oleaginous. In contrast, of over 400 known species in the genus Candida, only four are known to be oleaginous.

Several significant systematic changes were codified in the International Code of Nomenclature of Algae, Fungi and Plants (Melbourne Code) (McNeill et al. , 2012), such as elimination of the requirement that teleomorphic (spore-forming) and anamorphic (non-spore forming) species must be placed in different genera. Taxonomic revisions are currently underway, such as the recent removal of six species from the genus Cryptococcus and placement in the new genus Hannaella (Wang and Bai, 2008).

Some important trends emerge from these reports:

(1) Oleaginous yeasts are not clade-specific: they are scattered amongst multiple clades in phyla Ascomycota and Basidiomycota, as shown in Table 3 . This taxonomic diversity makes it risky to generalize when drawing conclusions about phenotypic or genotypic properties of specific yeast species or clades. It is important to point out that this taxonomic diversity suggests that oleaginicity may have developed multiple times independently, and thus there may be multiple mechanisms of lipid accumulation. Genomic and transcriptomic comparison of closely related species, or strains within a species, that accumulate different amounts of lipids under identical growth conditions may reveal lipid accumulation mechanisms.

(2) Lipid accumulation potential varies between closely related species, and among strains of the same species. It is therefore important to cite not only the species but also the strain ID number 
524 (including culture collection identifier such as UCDFST, CBS, or NRRL) when reporting yeast oil

525 productivity results. Furthermore, due to major changes in yeast taxonomy such as the revisions invoked by the Melbourne Code (McNeill, Barrie, 2012), it is important to cite the strain ID, as the species name of a given strain may change, but the ID number will remain constant. For example, some (but not all) strains previously identified as the oleaginous species Rhodotorula glutinis have been reassigned to species R. kratochvilovae (Sampaio et al. , 2001) or R. azoricum (Gadanho et al. , 2001) based on mating tests, or to Rhodosporidium babjevae, $R h$. diobovatum or Rh. sphaerocarpum based on ribosomal sequence analysis (Gadanho and Sampaio, 2002). Species names as listed in the most recent edition of the taxonomic treatise "The Yeasts: A Taxonomic Study" (Kurtzman, Fell, 2011a) and subsequent revisions and new species description publications are used in this review.

(3) New oleaginous yeast species continue to be discovered. Screens utilizing strains with indicators of oleaginicity have a higher hit rate than those using randomly selected strains. About 3-10\% of randomly selected yeasts screened were oleaginous. As there are currently about 1600 known yeast species, 50 to 160 of them may be oleaginous. As dozens of new yeast species descriptions are being published per year, the number of known oleaginous yeast species will undoubtedly continue to rise.

\subsection{Visualization, identification and quantification of lipids}

Methods of visualization, identification and quantification of polar and nonpolar lipids continue to improve. Analytical methods to identify and quantify lipids include gas chromatography-flame ionization detection (GC-FID), gas chromatography-mass spectrometry (GC-MS), thin layer chromatography-flame ionization detection (TLC-FID), matrix-assisted laser desorption and ionization and ionization time-offlight mass spectrometry (MALDI-TOF-MS), NMR, and HPLC. Some methods are more appropriate for lipid analysis of different types of materials. Volkman et al. (Volkman et al. , 1986) used TLC-FID to identify and quantify non-polar lipids in a variety of marine samples. Sitepu et al. (Sitepu, Sestric, 2013) used GC-FID to identify and quantify fatty acid methyl ester (FAME) from yeasts. Mondello et al. (Mondello et al. , 2004) analyzed different lipidic matrices to evaluate lipid analysis method by GC and GC-MS. Schiller et al. (1999) (Schiller et al. , 1999) found MALDI-TOF-MS effective in analyzing mixtures of lipids in biological samples, such as cell membranes. Moreau (2006) proposed HPLC-CAD (charged aerosol detector) as a potential tool to quantify a mixture of saturated and unsaturated lipid molecules. Henderson (Henderson, Lozada-Contreras, 2011) used atmospheric pressure ionization iontrap mass spectrometry to determine the membrane lipid composition of industrial strains of Saccharomyces cerevisiae.

Several hydrophobic, lipophilic stains are used to visualize lipid bodies within yeasts and other cells and tissues by spectrofluorometry and/or microscopy, reviewed in recent publications (Elle et al. , 2010, Fink et al. , 2012, Melo et al. , 2011, Radulovic et al. , 2013, Yen et al. , 2010) Commonly used dyes and selected examples of visualization of intracellular lipids are listed in Table 4.

In 2004, Kimura et al. published a spectrofluorometric method for estimating the lipid content of yeast cells using Nile red staining (Kimura et al. , 2004). We recently improved the consistency, throughput, and efficiency of this assay (Sitepu, Ignatia, 2012) by adjusting the Nile Red concentration, using kinetic reading rather than a single time point reading, scaling down to microtiter plate volumes, and other improvements (Sitepu, Ignatia, 2012). The method was validated by comparison to a gravimetric method, which was also improved and presented in the same publication. Quantification of 
total lipids by gravimetric methods involve solvent extraction of known amount of biological materials (Bligh and Dyer, 1959, Elsey et al. , 2007, Folch et al. , 1957). Briefly, cells were grown in a nitrogenlimited medium, harvested, freeze dried and weighed to determine dry cell mass. Lipids were extracted into Folch's Solvent, using a bead beater to lyse cells. The chloroform phase was evaporated under nitrogen and weighed to determine total lipid content as a percent of cell dry weight. Compared to the previously published method, the improved Nile Red assay correlated more closely with gravitational analysis $(\mathrm{r}=0.71)$.

\subsection{Fatty acid composition of oleaginous yeasts}

576

The storage lipids that accumulate in oleaginous yeasts are primarily diacylglycerols (DAG) and triacyl-glycerols (TAG). The fatty acid compositions of many yeast species have been reported (Augustyn, Kock, 1992, Botha and Kock, 1993, Jeffery, Kock, 1997, Sitepu, Sestric, 2013, Van Rensburg, Kock, 1995, Viljoen, Kock, 1986). Prior to development of ribosomal sequencing methods, fatty acid profiling was one of the methods used to identify yeast species (Augustyn, Kock, 1992, El Manyawi and Wogerbauer, 2000, Kock et al. , 1985). In fact, companies such as MIDI Labs (<http://www.midilabs.com>) still offer microbe identification service based on fatty acid profile. To generate a reference database for species identification, the lipid content of hundreds of yeast species has been characterized, for example,(El Manyawi and Wogerbauer, 2000, Kaneko, Hosohara, 1976, Ratledge and Wilkinson, 1988).

A small number of yeast species have demonstrated substantial productivity of both cell mass and lipid production. These species of oleaginous yeast are particularly attractive candidates for lipid production. For example, Cryptococcus curvatus (previously known as Apiotrichum curvatum or Candida curvata) was reported to accumulate up to 60\% lipid (Meesters et al., 1996, Moon et al. , 1978) (Ratledge, 1988, Ratledge, 1993). This species also grew to a cell mass density of $118 \mathrm{~g} \mathrm{~L}^{-1}$ when cultured on nitrogen sufficient medium with glycerol as a carbon source, with a lipid content of $25 \%$ (Meesters, Huijberts, 1996). Similar cell mass productivity was seen in cultures of Rhodosporidium toruloides, which reached a culture density of $100 \mathrm{~g} \mathrm{~L}^{-1}$ and $75 \%$ lipid content when cultivated under stressed conditions (Liu et al. , 2009). The lipid content and the total cell mass produced are culture dependent and highly variable (Ratledge and Wilkinson, 1988).

Both oleaginous and non-oleaginous yeasts contain lipids such as diacyl- and triacylglycerides, free fatty acids, sterols, carotenoids, and phospholipids. Under certain growth conditions (described in section 5.2), oleaginous yeasts accumulate intracellular triacylglycerols in lipid bodies (Radulovic, Knittelfelder, 2013, Ratledge, 1989, Rattray, 1988, Rattray et al. , 1975). Nitrogen starvation is known to trigger TAG accumulation in most oleaginous yeasts (Lundin, 1950, Rattray, 1988, Rattray, Scheibeci, 1975). One notable exception is Cryptococcus terricola, which can accumulate TAGs during logarithmic growth, before nitrogen depletion (Pedersen, 1961, 1962). Other yeasts able to accumulate oil during exponential phase are under investigation (Sestric, unpublished data). This is a valuable property for industrial production, allowing shorter production times and lipid production in nitrogen-rich substrates.

The fatty acid composition of intracellular TAGs is variable, and depends on the species of oleaginous yeast, growth phase, environmental conditions, and substrate and medium components. The fatty acid composition can fluctuate from strain to strain (Ratledge and Wilkinson, 1988, Sitepu, Ignatia, 2012, Sitepu, Sestric, 2013). As much as $80-90 \%$ of the neutral lipids are comprised of TAGs (Connor 
and Atsumi, 2010, Liu, Zhao, 2009, Meesters, Huijberts, 1996, Radulovic, Knittelfelder, 2013). Each fatty acid (FA) chain is 14-20 carbons in length bound to a glycerol backbone. The most common fatty acids are 16 or 18 carbons in length (C16 and C18, respectively), either saturated (no double bonds, such as $\mathrm{C} 16: 0$ ) or monounsaturated (one double bond, such as $\mathrm{C} 18: 1$ ). The most common FA of oleaginous yeasts are C18:1 (oleic acid), C16:0 (palmitic acid), and C18:0 (stearic acid) (Meesters, Huijberts, 1996). These are also the dominant FAs of plant oils used for production of biodiesel, such as canola and sunflower oil (Ageitos et al. , 2011, Rattray, 1988, Woodbine, 1959). Production of an oleochemical such as biodiesel using oleaginous yeasts therefore requires selection of a yeast species, and strain of that species, capable of producing the desired fatty acids, as well as identification of appropriate culture conditions. accumulation dominates when carbon is in excess (Lundin, 1950, Woodbine, 1959). During exponential growth phase, the C18:2 FA occurs in higher quantities, but decreases by stationary phase. The C18:0 and C18:1 FA become more prominent in stationary phase, and the addition of the double-bond in from C18:0 transitioning to the C18:1 occurs by the $\Delta^{9}$ desaturase (Hassan et al. , 1993, Meesters, Huijberts, 1996, Ykema et al. , 1988).

The fact that the fatty acid composition varies among oleaginous yeast species, among strains of the same species, and with the growth conditions has been known for many decades (Rattray, 1988, Rattray, Scheibeci, 1975, Viljoen, Kock, 1986, Woodbine, 1959). To quantify this effect in newly discovered as well as previously known oleaginous yeast species, Sitepu et al. (Sitepu, Sestric, 2013) cultured 69 oleaginous and non-oleaginous yeasts in nitrogen-depleted defined medium with excessive glucose $(120 \mathrm{~g} / \mathrm{L})$, and analyzed the fatty acid profile using GC-FID. The major fatty acids in most of the yeast

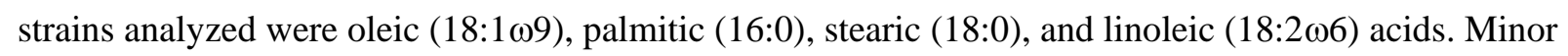
fatty acids were lignoceric acid (24:0), palmitic (16:1@7), behenic acid (22:0), myristic acid (14:0), $\alpha$ -


agreement with fatty acid profiles of yeast species as analyzed by other researchers (Amaretti et al. , 2012, Botha and Kock, 1993, Rattray, 1988). Fatty acid profiles vary significantly between species, to a lesser degree among strains of the same species, also for the same strain grown under different growth conditions. For example, total lipid content as well as fatty acid profile of several strains of Rhodotorula glutinis varied considerably between strains, and for the same strain grown under slightly different conditions (Sitepu, Sestric, 2013).

\section{Strain development}

An understanding of the genetic factors that contribute to oleaginicity is crucial for development of strains with improved lipid accumulation capabilities. Regulation of metabolic pathways and production of key enzymes can be manipulated to channel carbon into desired products. Genetic systems have been developed for selected oleaginous yeast species, particularly Yarrowia lipolytica. However, while wild strains of this species are capable of converting hydrophobic compounds into fatty acids and TAG, they are not particularly adept at converting carbohydrates to lipids. It should be noted that wild-type strains of other yeast species have superior baseline properties, such as utilization of a broader array of carbohydrates and conversion of them to lipids, inhibitor tolerance, and other industrially relevant 
characteristics. Thanks to lowering costs for genome sequencing, genetic tools for a broader range of yeast species can now be developed more easily.

\subsection{Comparison of relevant characteristics of oleaginous yeasts}

Several properties must be considered when selecting a yeast species, and a specific strain of that species, for laboratory research or for commercial development. For instance, an oleaginous yeast that thrives on corn stover hydrolysate, which is rich in glucose and xylose, may not be appropriate for conversion of dairy waste, which is rich in lactose.

Yeast strains can be obtained from a number of public culture collections such as the USDAAgricultural Research Service Culture Collection (NRRL, USA), Centraalbureau voor Schimmelcultures (CBS, the Netherlands), the Phaff Yeast Culture Collection at the University of California (UCDFST, USA), the American Type Culture Collection (ATCC, USA), and dozens of other collections around the world, as detailed in a recent review (Boundy-Mills, 2012). Researchers are advised to search online strain catalogs for alternate species names because they may have been amended due to taxonomic revisions; for example, strains referred to as Candida curvata or Apiotrichum curvatum in older literature should now be found under the currently valid name Cryptococcus curvatus. Online catalogs such as the CBS catalog with a "synonym" field may be searched for the older species names.

Some culture collections post very valuable strain characteristic data in their online catalogs. A fairly standardized panel of morphological, physiological and biochemical characteristics are used to classify and identify yeast species, including some properties that are coincidentally applicable to conversion of lignocellulosic hydrolysates to lipids. These include ability to grow on dozens of compounds as the sole carbon or nitrogen source, growth temperatures, osmotolerance, and much more. For example, the diagnosis of the genus Rhodosporidium Banno (1967) (Banno, 1967, Sampaio, 2011), which includes recently determined oleaginous species $R$. diobovatum, R. sphaerocarpum and $R$. paludigenum (Franklin, Decker, 2011a, Sitepu, Ignatia, 2012, Sitepu, Sestric, 2013), dictates that species in this genus, by definition, are able to utilize nitrate as a sole nitrogen source. Hydrolysates containing nitrate could therefore support growth of these species, but lipid accumulation may not be triggered until the nitrate is depleted. Conversely, diagnosis of the genus Trichosporon, which includes several oleaginous species, dictates that species are not able to utilize nitrate as a sole nitrogen source (Sugita, 2011), thus lipid production by these species would not be hindered by presence of nitrate. Ammonium can be utilized as a nitrogen source by all known yeast species, thus ammonium-pretreated hydrolysates provide a usable nitrogen source, but ammonium concentrations should be monitored to ensure it will be depleted at the stage of growth when lipid accumulation is desired.

In general, basidiomycetous yeast species are able to utilize a broader array of carbon sources than ascomycetous yeast species, and are more likely to be able to grow without supplemented vitamins (Kurtzman, Fell, 2011a). Over 60\% of the oleaginous species listed in Table 3 are basidiomycetous. Ascomycetous yeasts such as Saccharomyces cerevisiae and Yarrowia lipolytica have historically been more intensely studied, and genetic tools are more readily available for strain development. However, the numerous superior baseline characteristics may generate interest in developing a more expansive genetic toolbox for basidiomycetes.

Online catalogs of some culture collections such as the CBS yeast collection (<http://www.cbs.knaw.nl/collections/>) and the Portuguese Yeast Culture Collection (<http://pycc.bio- 
aware.com>) can be searched to select yeast strains with specific growth characteristics relevant to the desired process. This information is available in each yeast species description publication, and is also available in a compiled form in taxonomic treatises (Barnett et al. , 2000, Kurtzman, Fell, 2011a).

As summarized in Table 6, we recently compared the ability of representative strains of oleaginous yeast species to assimilate various carbon sources that are typically present in lignocellulose hydrolysates, including xylose, arabinose, cellobiose, mannose, galactose, rhamnose, and galacturonic acid (Sitepu et al. , 2014b). As expected, different oleaginous yeast species are able to utilize different carbon sources. On some carbon sources, some yeasts were able to grow immediately, while others exhibited a delay in growth. Delayed growth indicates that the species may benefit from acclimating to the carbon source before inoculation. Some yeasts such as Cryptococcus laurentii, Hannaella aff. zeae, Lipomyces starkeyi, and Trichosporon coremiiforme were able to utilize a broad variety of carbon sources, while others such as Trigonopsis variabilis and Yarrowia lipolytica were able to utilize very few of the carbon sources tested.

Inhibitors of microbial growth are produced as byproducts during lignocellulosic pretreatment and hydrolysis, including furans, aldehydes and organic acids. Hu et al. (Hu et al. , 2009) determined that some inhibitors affect growth of Rhodosporidium toruloides Y4 to a greater extent than others, and that growth inhibition was usually additive, sometimes synergistic, when multiple inhibitors were present. Growth in lab media containing six inhibitors at the concentrations typically found in hydrolysates had little influence on lipid yield and fatty acid composition, indicating that this strain has potential as an industrial strain. Similarly, concentrations of organic acids (Huang et al. , 2012c) and aldehydes (Huang et al. , 2011a) that inhibit lipid yield in Trichosporon fermentans. Concentrations of organic acids that inhibit lipid yield by $25 \%$ ranged from $3.0 \mathrm{mM}$ for caproic acid to $146.4 \mathrm{mM}$ for levulinic acid.

Options for dealing with these inhibitors include utilization of pretreatment and hydrolysis protocols that generate lower concentrations of inhibitors that affect lipid yield, such as $\mathrm{AFEX}^{\mathrm{TM}}$ pretreatment (Schwalbach et al. , 2012), or detoxification of the hydrolysate by biological or chemical processes (Galafassi et al. , 2012, Huang et al. , 2011b). Alternatively, oleaginous yeasts that are resistant to the inhibitors could be developed by mutation or genetic modification (Qi et al. , 2013). However, an easier approach would be to identify wild yeasts that are naturally resistant to these growth inhibitors. Sitepu et al. (Sitepu, Selby, 2014b) screened 48 oleaginous yeasts belonging to 46 species for ability to grow in the presence of the predominant inhibitors associated with lignocellulosic hydrolysates: 5(hydroxymethyl)furfural (HMF), furfural, and acetic acid. There was significant variation in ability to tolerate these inhibitors: strains Candida aff. tropicalis UCDFST 10-1087, Schwanniomyces occidentalis UCDFST 73-1 and Wickerhamomyces ficerii UCDFST 04-836 were able to grow in the presence of all inhibitors tolerated. However, these yeasts could utilize relatively few carbon sources, and accumulate relatively low levels of intracellular lipids.

These results suggest that identification of yeast strains able to utilize the carbon sources and tolerate the inhibitors present in a specific hydrolysate may be a more fruitful strategy than identifying a yeast able to grow under all possible conditions.

While most yeast species grew as diffuse suspensions of cells, a few species flocculated, forming larger clumps of cells. Strain Trichosporon coremiiforme UCDFST 88-108.4 flocculated into sizeable pellets, adding valuable characteristics to this species that has been shown to be useful for production of lipids from corn cob hydrolysate (Huang et al. , 2013b) and industrial waste water (Chen et al. , 2012a). 
This property may enable simpler downstream processing such as dewatering. It is important to note that the degree of flocculation varies with the species, the strain, and the growth conditions.

Use of yeasts able to grow in the absence of costly nutrients such as vitamins would reduce production costs. Furthermore, vitamin synthesis could generate valuable co-products (Dunn, 1952). A small percentage of yeasts can grow in vitamin-free media because they can synthesize their own vitamins. This is more common among basidiomycetes than ascomycetes (Kurtzman, Fell, 2011a). For example, none of the twelve currently known species of the ascomycetous genus Myxozyma can grow in vitamin-free media (Kurtzman and Smith, 2011), but seven of the nine known species of the basidiomycetous genus Rhodosporidium can (Sampaio, 2011). Recent work by Sitepu et al. showed that 38 out of 48 oleaginous yeast strains tested were able to grow in vitamin-free media (Sitepu, Selby, 2014b).

In addition to affecting production costs, certain vitamins are also directly involved in synthesis of fatty acids. Biotin is a prosthetic group present in acetyl CoA carboxylase. Its role is to activate a molecule of carbon dioxide and facilitating its binding to Acetyl Coenzyme A, in order to form malonyl Coenzyme A. This is the first step in fatty acid synthesis in microorganisms. In the process, a carboxybiotin intermediate is formed at the expense of the hydrolysis of ATP (Berg et al. , 2006). Pantothenic acid is a cofactor present both in the acyl carrier protein (ACP) as well as Acetyl Coenzyme A (Berg, Tymoczko, 2006). ACP is a polypeptide that works as a large prosthetic group responsible for activating the intermediates during chain elongation in the context of fatty acid synthesis. Pantothenic acid contains a sulfhydryl group capable of binding to the intermediates via a high energy thioester bond, thus increasing their reactivity and facilitating the reactions occurring during fatty acid synthesis. Further analysis of growth in the absence of individual vitamins is needed to determine which oleaginous yeast species can grow and produce lipids in the absence of supplemented biotin and/or pantothenic acid. This may eliminate the need to supplement growth medium with rather expensive micronutrients (Franklin, Decker, 2011a, Schwalbach, Keating, 2012).

\subsection{Examination of enzymatic and genetic factors that contribute to oleaginicity}

After nitrogen is depleted from the medium, cell division stops, and protein and nucleic acid synthesis by yeasts cease. In non-oleaginous yeasts, lipid synthesis occurs at a low level, and carbon excess is diverted into polysaccharides such as glycogen, glucan and mannan (Ageitos, Vallejo, 2011, Ratledge, 2002). Oleaginous yeasts, on the other hand, continue to synthesize and accumulate intracellular lipids that are stored in lipid bodies primarily as triacylglycerides (TAG) (Ageitos, Vallejo, 2011, Radulovic, Knittelfelder, 2013, Ratledge, 2004).

Enzymes and metabolites responsible for channeling glucose to fatty acid synthesis rather than carbohydrates have been explored using metabolomic and genomic tools. Key metabolic pathways leading to TAG accumulation in oleaginous yeasts are diagrammed in detail in other publications (Evans et al. , 1985, Garay et al. , 2014, Liu et al. , 2013). Important regulatory controls are summarized in Figure 3.

Over 30 years ago, Ratledge's group explored the regulatory roles that selected metabolites and enzymes play in accumulation of lipids in oleaginous species including Rhodosporidium toruloides, and

773 identified several factors that affect lipogenesis following nitrogen depletion: 
(1) accumulation of ATP and depletion of AMP (Boulton and Ratledge, 1983)

(2) inactivation of mitochondrial $\mathrm{NAD}^{+}$:isocitrate dehydrogenase (Botham and Ratledge, 1979)

(3) transport of citrate from the mitochondrion to the cytosol (Evans et al. , 1983)

(4) expression of cytosolic ATP:citrate lyase (Boulton and Ratledge, 1981, Boulton and Ratledge, 1983)

(5) feedback inhibition of ATP:citrate lyase activity and citrate efflux by long chain fatty acid acylCoA esters (Boulton and Ratledge, 1981, Evans and Ratledge, 1983).

These factors were supported by several observations beyond yeasts. ATP:citrate lyase has been linked with oleaginicity in plants and higher animals (Fritsch and Beevers, 1979, Kornacker and Lowenstein, 1965, Srere, 1975, Yen and Mack, 1980). Malic enzyme has been associated with lipogenesis in mammals (Frenkel, 1975). Because malate is the counterion for release of citrate from the mitochondrion, it could provide cytosolic citrate as well as NADPH for cytosolic synthesis of fatty acids.

Ratledge's group found that ATP:citrate lyase (ACL) activity was detected in oleaginous yeasts, but not in most non-oleaginous yeasts (Boulton and Ratledge, 1981, Ratledge, 2002, Ratledge and Wynn, 2002). Furthermore, the CFR-1 mutant of Rhodosporidium toruloides deficient in ATP:citrate lyase produced insignificant amounts of lipids (Jacob, 1993). Citric acid is an acetyl-CoA donor for fatty acid synthesis in the cytoplasm in oleaginous yeasts, and ACL controls the flux of carbon into storage lipids (Botham and Ratledge, 1979, Ratledge, 2002). They also examined the correlation between intracellular lipid accumulation and enzymatic activities, and determined that malic enzyme controls the level of lipid accumulation, as it is the source of NADPH for fatty acid synthase (Ratledge, 2002, Ratledge and Wynn, 794 2002).

In recent years, advanced metabolomic and genomic tools have uncovered regulatory controls of microbial lipid accumulation. Metabolic flux analysis using ${ }^{13} \mathrm{C}$-labeled metabolites has been used to explore the regulation of lipid accumulation in the oleaginous microalga Chlorella protothecoides, and led to metabolic engineering strategies for improving lipid accumulation (Xiong et al. , 2010). Similar studies of the oleaginous yeast Trichosporon cutaneum revealed that NADPH generated by the cytosolic malic enzyme, and acetyl-CoA generated via citrate from cytoplasmic ACL, were associated with excess lipid accumulation (Liu et al. , 2012c).

A recent comparative genomics study of three oleaginous and four non-oleaginous fungal genomes confirmed that the ACL pathway is found in the oleaginous fungi but not the non-oleaginous fungi studied (Vorapreeda et al. , 2012). In addition, Vorapreeda et al. identified amino acid degradation genes in the oleaginous fungi genomes that could generate acetyl-CoA, and an alternate lysine biosynthesis pathway that does not consume acetyl-CoA. However, very few species were included in this study. The taxonomic diversity of oleaginous yeast species, intermingled with non-oleaginous species, implies that there may be multiple mechanisms of lipid accumulation in oleaginous fungi. Analysis of additional oleaginous species, or multiple strains of the same species that accumulate varying amounts of lipids, may uncover additional regulatory elements. For example, analysis of the genome sequences of additional oleaginous yeasts such as the recently released Rhodosporidium toruloides MTCC 457 (Kumar et al. , 2012) has helped confirm this correlation. A multi-omic map of lipid synthesis process in $R$. toruloides NP11 revealed a novel fatty acid synthase predicted to participate in lipid synthesis pathways absent in yeasts with lower lipid accumulation potential (Zhu et al. ,2012). Transcriptomic and proteomic analysis 
815 correlated nitrogen limitation with induction of lipogenesis, recycling of nitrogenous compounds, and 816 autophagy.

\subsection{Genetic modifications to increase or alter fatty acid production}

Improvement of wild microbial strains has been a leading strategy for numerous industrial applications ranging from food and beverage production to pharmaceuticals. Selection of a parent strain with promising baseline characteristics is a crucial step in strain development. In the case of microbial lipid production, two very different strategies are employed: improving resident metabolic pathways in lipid-producing microbes (Liang and Jiang, 2013, Liu, Redden, 2013, Trimbur, Im, 2012a), or placing fatty acid synthesis pathway genes from oleaginous microbes into industrial microbes such as $E$. coli or Saccharomyces cerevisiae (Kamisaka, 2010, Shi, Valle-Rodriguez, 2011). This review focuses on the former.

Under normal conditions $S$. cerevisiae does not accumulate significant quantities of lipid, and is not classified as an oleaginous species. Understanding the differences in lipid synthesis and accumulation between oleaginous and non-oleaginous species may elucidate key enzymes and bottlenecks in carbon flow of FA synthesis (Sandager et al. , 2002, Schmidt, 1947). A study by Sandager et al. demonstrated that deletions of $S$. cerevisiae genes ARE1, ARE2, LRO1, and DGA1 genes resulted in production of lipid bodies in this normally non-oleaginous species (Sandager, Gustavsson, 2002). The ARE1 and ARE2 genes are similar, both encoding an acyl-CoA:sterol acyltransferace (ASAT), while the LROI encodes a phospholipid:diacylglycerol acyl-transferase (PDAT). PDAT generates TAGs without the use of acylCoA. Phospholipids and diacylglycerols can also be redistributed to TAG production with PDAT. While these enzymes affected TAG production, DGAl was deemed most important in $S$. cerevisiae. The DGAl gene is an acyl-CoA:diacylglycerol acyltransferase (specifically a DGAT2) that catalyzes conversion of a diacylglycerol (DAG) and acyl-CoA to a triacylglycerol (TAG) (Sandager, Gustavsson, 2002, Weiss and Kennedy, 1956). While the mutation was not fatal, the disruption of this gene leads to a lipid body-free phenotype. The cell still has the enzymes to make FA for phospholipids, but cannot store TAG.

In studies of oleaginous yeasts, molds, bacteria and microalgae, several strategies that have been identified that successfully increased lipid accumulation (Liang and Jiang, 2013). These include:

These approaches have been applied to few yeast species, primarily S. cerevisiae and Y. lipolytica. Unlike other oleaginous yeasts discussed in this review, wild strains of Yarrowia lipolytica accumulate oil from hydrophobic substrates rather than carbohydrates. The genome of this yeast species was sequenced to facilitate development of genetic tools and metabolic pathway enhancements (reviewed in (Beopoulos et al. , 2009, Beopoulos et al. , 2010). Genetic manipulation has resulted in development of strains with increased or decreased ability to form lipid bodies. Deletion of the glycerol-3-phosphate dehydrogenase gene (GUT2) redirected carbon flux toward TAG assembly, with a 3-fold increase in lipid accumulation 
(Beopoulos et al. , 2008). In contrast, deletion of POX genes encoding proteins responsible for fatty acid uptake resulted in formation of fewer, smaller lipid bodies (Mlíčková et al. , 2004). Significant and commercially valuable alteration of the fatty acid composition has also been achieved in this yeast species. Numerous patents cover the introduction of heterologous genes encoding proteins of the $\omega-3$ PUFA and $\omega-6$ PUFA biosynthetic pathways into Yarrowia to introduce production of the high-value nutritional lipids docosahexaenoic acid (Damude et al. , 2009) and eicosapentaenoic acid (Damude et al. , 2011).

Proteomic analysis has aided SCO research as well (Liu et al. , 2011, Zhu, Zhang, 2012). Protein extracted from log and stationary growth cells of the oleaginous yeast Rhodosporidium toruloides NP11 showed metabolic shifts. Using S. cerevisiae as a reference, it was observed that the TCA cycle genes were down regulated as the TAG synthesis genes were up regulated. Additionally, pathways that regulated the carbohydrate and protein production enzymes were down regulated when cells were in a reduced concentration of nitrogen (Liu, Zhao, 2009). Cells also began creating internal nitrogen sources by the catabolism of adenosine monophosphate (AMP) to make ammonium, and amino acid metabolism occurred (Liu, Zhao, 2009, Ratledge and Wilkinson, 1988).

Direct production of biodiesel rather than TAGs in microbes would reduce processing costs. Genes for ester synthesizing pathways have been introduced into non-oleaginous microbes Saccharomyces cerevisiae and $E$. coli to induce direct production of fatty acid ethyl esters directly from carbohydrates (Kalscheuer et al. , 2006, Schmidt-Dannert and Holtzapple, 2009, Steen, Kang, 2010).

In addition to high oil and high cell mass production, other desirable properties of robust industrial strains of oleaginous yeasts include ability to utilize the nutrients present in the particular hydrolysate of interest, tolerance of inhibitors, osmotolerance, production of a suitable array of fatty acids for the end product, and fast growth. Additional desirable properties could include utilization of glucose and xylose simultaneously to reduce processing time (Hu et al. , 2011); tolerance of higher temperatures used for enzymatic hydrolysis of pretreated lignocellulose, to allow simultaneous saccharification and fermentation (Liu et al. , 2012b); and ability to be lysed easily to facilitate oil recovery. These improvements could lead to consolidated bio-processing, reducing costs.

\section{Process development}

It has been known for decades that culture conditions such as stage of growth, carbon source and concentration, aeration, temperature, nitrogen source, and micronutrients affect the concentration and composition of lipids (Woodbine, 1959). During World War I, Lindner outlined three requirements for microbial lipid synthesis: adequate carbohydrate supply, aeration, and a young inoculum (Woodbine, 1959). In the intervening decades, significant increases in intracellular lipid accumulation have been reported repeatedly through optimization of culture conditions such as $\mathrm{C} / \mathrm{N}$ ratio, timing of introduction of $\mathrm{N}$, minerals, $\mathrm{pH}$, and temperature. Recent examples include optimization of Lipomyces starkeyi grown on glucose and xylose (Zhao et al. , 2008), Rhodosporidium toruloides grown on glucose with various $\mathrm{C} / \mathrm{N}$ and C/P ratios (Wu et al. , 2010), Trichosporon cutaneum grown in medium containing various ratios of glucose:xylose (Hu, Wu, 2011); L. starkeyi AS 2.1560 grown in various ratios of glucose, xylose and cellobiose (Gong et al. , 2012) or glucose and mannose (Yang et al. , 2014); T. fermentans grown on pretreated waste molasses (Zhu et al. , 2008), Rhodosporidium toruloides grown on a mixture of glucose, xylose and arabinose (Wiebe et al. , 2012), and Lipomyces starkeyi grown on sewage sludge (Angerbauer et al. , 2008). 
Consolidate bioprocessing processes, such as simultaneous saccharification and fermentation, are being used to streamline production of fuels and chemicals. For example, in a recent screen of 1200 yeasts, a strain of Cryptococcus terricola attained a lipid content of over $61 \%$ when grown on starch (Tanimura et al. , 2014a).

\subsection{Conversion of lignocellulosic hydrolysates to yeast oil}

There have been numerous reports of conversion of various waste products and hydrolysates to oil using oleaginous yeasts. In 1922, Lindner cultivated E. vernalis (now called Guehomyces pullulans) on waste sulphite liquor, resulting in yeast cells containing 45\% lipid (Lindner, 1922). Lundin's group was able to cultivate $R$. gracilis (now called Rhodosporidium toruloides) on molasses or wood hydrolysates, obtaining up to $64 \%$ lipid (Lundin, 1950, Tornqvist and Lundin, 1951). Conversion of hydrolysates and waste products to oil by oleaginous yeasts have been discussed in many publications and summarized in reviews (Ageitos, Vallejo, 2011, Angerbauer, Siebenhofer, 2008, Chi et al. , 2011, Galafassi, Cucchetti, 2012, Li, Du, 2008, Meng, Yang, 2009, Rattray, 1988, Rattray, Scheibeci, 1975, Rossi et al. , 2011). Examples of recent feedstocks used for single cell oil production are listed in a recent review by Huang et al. (Huang, Chen, 2013a), and include raw materials from the food industry (molasses, tomato waste, sweet sorghum extracts, etc.), hydrophilic materials (molasses), and hydrophobic materials (vegetable oils, industrial fats). This review also lists the estimated costs of various feedstocks. In addition, there have been many recent reports of hydrolysates of various plant materials have been converted to lipids using oleaginous yeasts, as listed in Table 5. Conversion of wastes and plant materials that have been converted to oil using oleaginous yeasts without prior hydrolysis were recently summarized (Leiva-Candia, Pinzi, 2014).

Because yeasts lack significant cellulolytic activity, lignocellulosic material must be pretreated and enzymatically hydrolyzed to release free sugars prior to conversion to lipids by oleaginous yeasts. This review briefly covers some salient aspects of the complex process of pretreatment and hydrolysis; interested readers are invited to read other publications for further information (Alvira et al. , 2010, Dijkerman et al. , 1997, Gírio et al. , 2010, Van Dyk and Pletschke, 2012). Lignocellulosic materials available for conversion include many waste streams such as agricultural, food processing, forestry, industrial and municipal, as well energy crops (Van Dyk and Pletschke, 2012). The composition of a given feedstock varies by region and season (Food and Agriculture Organization of the United Nations, 2009). Hydrolysates of these materials vary significantly in properties that affect yeast growth including $\mathrm{pH}$, the amount and type of nitrogen and carbon sources, and amounts and types of fermentation inhibitors such as organic acids and furans. It is therefore important to select and develop oleaginous yeast strains that are able to utilize the carbon and nitrogen sources, tolerate the inhibitors, and both grow and accumulate oil at the $\mathrm{pH}$ of the target feedstock hydrolysate.

Lignocellulose is composed of several classes of polymers including cellulose, hemicellulose, lignin and pectin (Figure 2). The relative amounts and types of these polymers varies in different plants (Van Dyk and Pletschke, 2012). Pretreatment is necessary to open up and separate these polymers, degrading the crystalline structure and making each of the polymers more accessible for enzymatic hydrolysis. A number of biological, physical, chemical, and physico-chemical pretreatment protocols have been developed that are appropriate for different types of plant materials (Alvira, Tomás-Pejó, 2010, Mosier et al. , 2005, Wyman, 1999, Wyman et al. , 2005). Because these pretreatment protocols generate 
different product profiles, a pretreatment regimen must be selected that will generate products that are compatible with the properties of the target yeast strain, or vice versa.

After pretreatment, the lignocellulosic material is hydrolyzed to release oligo- and monosaccharides. In nature, enzymes of degraders such as bacteria and fungi perform these functions. In industrial applications, these enzymes are harnessed in the form of commercially developed cellulase cocktails, comprised of cellulases, hemicellulases, pectinases and ligninases. More information about enzymatic activities of cellulases can be found in reviews (Alvira, Tomás-Pejó, 2010, Gírio, Fonseca, 2010, Van Dyk and Pletschke, 2012). The primary products of enzymatic hydrolysis are illustrated in Figure 2.

Cellulose is the primary structural component, made of polymers of glucose joined by $\beta-1,4$ linkages, linked by hydrogen bonds to form the crystalline structure. The cellulose component is surrounded by a matrix of hemicellulose, pectin and lignin. After pretreatment, which separates the components, hydrolysis of cellulose by cellobiohydrolase, endoglucanase, and $\beta$-glucosidase releases glucose, cellobiose, and other glucose oligomers.

Hemicellulose is comprised of various polymers that vary depending on the species of plant, and can include xylan (the most abundant), galactan, mannan and arabinan. Hydrolysis of hemicellulose by hemicellulases such as endo-xylanase, endo-mannanase, $\alpha$-glucuronidase, $\alpha$-galactosidase, and others releases monomers and oligomers that vary depending on the composition of the hemicellulose of the plant species and the activity of the hydrolytic enzyme. These can include D-xylose, D- or L- arabinose, mannose, galactose, and glucose (Beg et al. , 2001, Gírio, Fonseca, 2010).

Pectin is also a highly diverse class of polysaccharides. It retains water, and is present in higher concentrations in certain high moisture plant materials such as fruits. They are digested by pectinases such as galacturonase, releasing many sugars such as galacturonic acid (the primary component), rhamnose, arabinose, galactose, and others (Van Dyk and Pletschke, 2012, Willats et al. , 2006).

Lignin is a heterogenous, cross-linked, hydrophobic polymer of phenolic monomers. The relative abundance of monomers varies with the type of plant. It is viewed as an obstacle to enzymatic hydrolysis of cellulose and hemicellulose (Dijkerman, Bhansing, 1997). It is often removed from the pretreated material rather than hydrolyzed, as degradation generates breakdown products that can be toxic to degradative enzymes and fermentative microbes, and the lignin itself could instead be recovered to be burned in boilers to generate energy (Romaní et al. , 2010, Van Dyk and Pletschke, 2012). Breakdown or removal of lignin can accomplished by mechanical, thermal, chemical or enzymatic processes such as acid hydrolysis, steam treatment or alkaline treatment (Van Dyk and Pletschke, 2012). Degradation of lignin can release a broad variety of polyphenols and low molecular weight phenolics, such as syringaldehyde, 4-hydroxybenzoic acid, vanillic acid, and vanillin, and other compounds that can be inhibitory to enzymes or fermentative microbes (Palmqvist and Hahn-Hagerdal, 2000, Parawira and Tekere, 2011, Van Dyk and Pletschke, 2012). These compounds also have the potential to be recovered as high-value chemical intermediates.

Conversion of a variety of waste products to oil using oleaginous yeasts has been reported for many decades (Stanier, 1946, Turcotte and Kosaric, 1989, Woodbine, 1959) such as wood hydrolysates (Lundin, 1950, Tornqvist and Lundin, 1951) and molasses (Kleinzeller, 1944). Koch and colleagues produced a "tasty, dry, nutritive yeast" with a "pleasant, peanut-like taste" with a fat content of over $25 \%$ on an industrial scale in the 1940s by growing Candida reukaufii (now called Metschnikowia reukaufii) on

980 molasses with additions of whey (Woodbine, 1959). Other waste products used include bananas, food 
waste, beet pulp extract, corn steep liquor, and starch using yeast species such as Cryptococcus curvatus, Rhodosporidium toruloides, Rhodotorula glutinis (Atabani, Silitonga, 2012, Lundin, 1950, Stanier, 1946, Woodbine, 1959). Conversion of various carbon sources and hydrolysates to oil by numerous yeast species was reviewed recently by Ageitos et al. (Ageitos, Vallejo, 2011), and Huang et al. 2013 (Huang, Chen, 2013a). Several additional recent reports of conversion of various lignocellulosic hydrolysates and carbon sources to oil using oleaginous yeasts are listed in Table 5. Examples of relatively high lipid yield include $15.73 \mathrm{~g} / \mathrm{L}$ produced by Trichosporon fermentans grown on sugar cane bagasse hydrolysate (Huang, Wu, 2012b), 12. 3 g/L for T. cutaneum grown on corn cob hydrolysate (Gao et al. , 2014) and 11. $5 \mathrm{~g} / \mathrm{L}$ for $T$. fermentans grown on rice straw hydrolysate (Huang et al. , 2009a).

These publications were all performed at lab scale, and all, except the study by Sitepu et al. (Sitepu, Sestric, 2013) utilized frequently studied oleaginous yeast species. Further improvements in productivity could be achieved using yeasts better suited to the conditions of hydrolysates. To address this issue, Sitepu et al. (Sitepu et al. , 2014a) screened 39 yeasts for lipid accumulation in both synthetic and authentic corn stover hydrolysate containing both glucose and xylose (Schwalbach, Keating, 2012). Most of these yeasts grew in synthetic medium containing the two carbon sources. Of ten promising strains that were then tested on authentic AFEX TM -pretreated corn stover hydrolysate, only three grew well, possibly due to presence of growth inhibitors that were not present in the synthetic formulation. Cryptococcus humicola strains UCDFST 10-1004 and UCDFST 12-717 exhibited the highest cell mass production and lipid accumulation. These two strains were isolated from Papalia, Sulawesi, Indonesia. It is important to emphasize that the final oil content per gram dry weight of cells is only one of many values to be taken into consideration when optimizing oil production. The overall efficiency of conversion of carbohydrate to lipid (the lipid coefficient) and the production rate are also important considerations.

\subsection{Optimization of process parameters to increase lipid production}

As described in reviews (Ratledge, 2002, Ratledge and Wynn, 2002, Rattray, 1988, Rattray, Scheibeci, 1975, Woodbine, 1959), it has been known for decades that yeast lipid content is affected by many factors including the yeast species, yeast strain, stage of growth, carbon source and level, aeration rate, temperature, presence of alcohol, nitrogen level, nitrogen source, phosphorus level, thiamine, biotin, $\mathrm{pH}$, and acclimatization to a carbon source. Several studies have applied this knowledge to optimize process parameters to increase lipid and cell mass production when oleaginous yeasts were grown on various carbon sources and waste streams (Angerbauer, Siebenhofer, 2008, Beopoulos, Desfougeres, 2010, Gong, Wang, 2012, Thiru et al. , 2011, Wiebe, Koivuranta, 2012, Wu, Hu, 2010, Zhao, Kong, 2008, Zhu, Zong, 2008).

\subsubsection{Nitrogen source and level.}

The effects of nitrogen source and levels on total lipids and on fatty acid profiles has been analyzed with varying results, depending on the yeast species being examined (Evans and Ratledge, 1984, Husain and Hardin, 1952, Turcotte and Kosaric, 1989, Yoon et al. , 1982). In a study of 17 species of yeasts, Evans and Ratledge (Evans and Ratledge, 1984) observed that lipid content varied little among most species grown in ammonium chloride, asparagine and glutamate; an exception was Rhodosporidium toruloides, which had much higher lipid accumulation when grown on organic nitrogen than inorganic nitrogen. Hansson and Dostalek (Hansson and Dostalek, 1986a, b) observed almost identical growth 
1023

1024

1025

1026

1027

1028

1029

1030

1031

1032

1033

1034

1035

1036

1037

1038

1039

1040

1041

1042

1043

1044

1045

1046

1047

1048

1049

1050

1051

1052

1053

1054

1055

1056

1057

1058

1059

1060

1061

1062

1063

1064

curves with Cryptococcus albidus grown in several nitrogen sources. In a comparison of yeast cell mass and lipid yields, Husain and Hardin observed in 1951 (Husain and Hardin, 1952) that Rhodosporidium toruloides (formerly called Rhodotorula gracilis) produces highest lipids and cell mass when grown in urea, and that lipid productivity was higher in ammonium chloride than in ammonium sulfate.

Sitepu et al. (Sitepu, Sestric, 2013) cultured dozens of yeast strains in a defined low nitrogen medium (Medium A (Suutari et al. , 1990)) for three days (Culture A), for five days (Culture B), or for a total of five days with a shift from low nitrogen to nitrogen-free medium at three days (Culture C). Total lipid was measured gravimetrically. This work confirmed earlier observations that nitrogen deficiency induces higher lipid accumulation in oleaginous yeasts, as 35 out of 37 oleaginous yeast species tested had highest overall lipid content in Culture $\mathrm{C}$.

\subsubsection{Carbon/nitrogen ratio}

The $\mathrm{C} / \mathrm{N}$ ratio in the growth medium has been observed to have a strong effect on lipid production in many yeast species, as summarized in many book chapters and reviews (Lundin, 1950, Ratledge, 1989, Rattray, 1988, Turcotte and Kosaric, 1989, Woodbine, 1959). Most known oleaginous yeasts accumulate more lipid as the $\mathrm{C} / \mathrm{N}$ ratio rises to a certain point, and lipid accumulation is triggered when nitrogen is depleted from the medium. For example, increasing the molar $\mathrm{C} / \mathrm{N}$ ratio from 150 to 350 increased the glucose-to-lipid conversion yield by Rhodotorula glutinis from 0.25 to 0.40 , but increasing the $\mathrm{C} / \mathrm{N}$ ration further had detrimental effects on yeast cell viability (Beopoulos, Cescut, 2009). Cryptococcus terricola is an exception: it has been observed to accumulate lipid during rather than after logarithmic growth, and in the presence of excess nitrogen (Pedersen, 1961, 1962). Presence of more than one carbon source greatly affects lipid productivity: in Yarrowia lipolytica, the optimal molar $\mathrm{C} / \mathrm{N}$ ratio for best lipid production was 35 if only glucose was used, but 180 if a combination of glucose plus glycerol was used . Kraisintu et al. (Kraisintu, Yongmanitchai, 2010) measured cell mass and lipid production of one strain of $R$. toruloides under several conditions including varying $\mathrm{C} / \mathrm{N}$ ratio. They found that the nitrogen source, glucose level and $\mathrm{C} / \mathrm{N}$ ratio had significant effects. In agreement with previous reports, increasing the $\mathrm{C} / \mathrm{N}$ ratio decreased cell mass but increased lipid content; overall lipid productivity was increased only slightly at the highest $\mathrm{C} / \mathrm{N}$ molar ratios of 115 and 140, with a maximum cell lipid content of $62.3 \%$ at $\mathrm{C} / \mathrm{N}$ ratio of 140 .

\subsubsection{Aeration rate and dissolved oxygen (DO) concentration}

It has been known for almost 100 years that thorough aeration promotes lipid accumulation by oleaginous yeasts (Woodbine, 1959). Before the development of modern bioreactors, less successful attempts to increase the dissolved oxygen content of oil-accumulating yeast cultures included growth in shallow pans, and trickling media over suspended fabric belts (Woodbine, 1959). However, increasing aeration is not guaranteed to increase lipid accumulation. Increased lipid production has been observed in S. cerevisiae and C. utilis in some cases under aerobic growth, and in other conditions under anaerobic growth (Rattray, Scheibeci, 1975).

Optimizing overall productivity, not just final cellular oil content, must be the goal of process development. For example, in a study of the effects of aeration rate on both cell mass and lipid accumulation by Rhodosporidium toruloides (formerly called Rhodotorula gracilis), faster growth rates correlated with lower final lipid content; the lipid production rate was constant at about $0.012 \mathrm{~g} \mathrm{lipid} / \mathrm{g}$ dry cell mass / hr (Choi et al. , 1982). Turcotte (Turcotte and Kosaric, 1988) observed that in batch cultures of $R$. toruloides, oxygen demand increased for a time shortly after nitrogen depletion from the 
medium, then dropped. Correlation of oxygen demand with lipid production appears to vary by yeast species, and must be determined empirically.

\subsubsection{Sugar type and concentration}

As discussed in section 4.1, different yeast species are able to utilize different carbohydrates that comprise lignocellulosic hydrolysates. A yeast strain should be selected that is able to convert the majority of sugars present in a given hydrolysate into the desired lipids. Furthermore, a yeast must be selected that can tolerate the osmolarity of the hydrolysate. For example, yeast strain Rhodosporidium toruloides DMKU3-TK16 produced increasing lipid yield in media containing up to $70 \mathrm{~g} / \mathrm{L}$ glucose, but lipid and cell mass production decreased at higher glucose concentrations (Kraisintu, Yongmanitchai, 2010). The yeast strain Rhodotorula glacialis DBVPG 4785, on the other hand, continued to increase in lipid production and cell mass up to an optimal glucose concentration of $120 \mathrm{~g} / \mathrm{L}$ (Amaretti et al. , 2010).

The effect of high sugar content on lipid production varies with the yeast species. A particularly marked difference is seen when comparing Crabtree negative and Crabtree positive yeasts. Crabtree positive (respiratory deficient) yeasts such as Saccharomyces cerevisiae and Yarrowia lipolytica are subject to catabolite repression, but Crabtree negative (respiratory sufficient) yeasts such as Rhodotorula glutinis, Candida utilis and Pichia stipitis are not. It has been known for quite some time that while Crabtree positive yeasts produce less lipid under high glucose concentrations, Crabtree negative species accumulate higher total lipids (Rattray, Scheibeci, 1975). This was observed with recently discovered Crabtree negative oleaginous yeast species Rhodotorula glacialis (Amaretti, Raimondi, 2010). Most of the oleaginous species in Table 3 are Crabtree negative, and may be more suitable choices for conversion of high-sugar hydrolysates than Crabtree positive yeasts.

Sitepu et al. (manuscript in preparation) compared cell mass (measured by OD600 and cell dry weight) and lipid accumulation (measured gravimetrically (Sitepu, Ignatia, 2012)) of six oleaginous yeasts grown in $100 \mathrm{~mL}$ of Medium A containing HMF $(0.15 \mathrm{mg} / \mathrm{mL})$ and furfural $(1.0 \mathrm{mg} / \mathrm{mL})$ plus glucose, xylose or both. Candida intermedia UCDFST 11-455 and UCDFST 11-472; Candida cf. kazuoi UCDFST 10-874; Candida cf. sagamina UCDFST 10-1002; Candida $\mathrm{cf}$. tenuis UCDFST 11-461 and Cryptococcus magnus UCDFST 10-900 grew to higher cell density on glucose than on xylose, but had higher overall oil productivity on xylose as a sole carbon source than on glucose. (This finding is in contrast to results seen recently by Wiebe et al. (Wiebe, Koivuranta, 2012) in a study of Rhodosporidium toruloides, in which glucose gave the highest lipid production.) Strain Cryptococcus magnus UCD-FST $10-900$ had the highest lipid yield of the six strains tested, on all three media, with close to $60 \%$ oil by cell dry weight.

\subsection{5. pH}

On an industrial scale, control of $\mathrm{pH}$ adds to production costs. Use of yeasts that can accumulate oil despite fluctuations in $\mathrm{pH}$ or acidification of the media would be preferable. Yeasts in general are acidtolerant, which has made them useful for low $\mathrm{pH}$ food and beverage fermentations such as wine, pickles, olives and kimchi. Acidified YM medium ( $\mathrm{pH}$ 3.9) is a simple selective media that has been used for many decades to cultivate yeasts out of mixed populations containing both yeasts and bacteria (Miller and Webb, 1954). Acidic conditions are also used industrially to deter growth of many potentially contaminating bacteria, such as conversion of sugarcane bagasse to ethanol. No deleterious effects of low pH on oil accumulation in oleaginous yeasts have been observed (Turcotte and Kosaric, 1989). For 
example, Kessell (Kessell, 1968) observed no overall change in lipid productivity in Rhodosporidium toruloides grown in $\mathrm{pH} 3.0,4.5$ or 6.0 .

\subsubsection{Temperature}

Decreased growth temperature from 25C to $10 \mathrm{C}$ resulted in increased total lipid and phospholipid,

\subsection{Manipulation of culture conditions to alter the fatty acid profile}

Certain fatty acids are optimal for use in biodiesel (Table 1). Based on these criteria, yeast oil high in oleic acid would have superior fuel performance properties. Predicted biodiesel properties of several oleaginous yeast oils were recently summarized (Leiva-Candia, Pinzi, 2014)

Fatty acid profiles have been determined for many oleaginous yeast species (Kaneko, Hosohara, 1976, Ratledge, 2002, Ratledge and Wynn, 2002, Sitepu, Sestric, 2013, Viljoen et al. , 2004). The most prevalent fatty acids are oleic acid (18:1 $\omega 9)$, palmitic acid (16:0), linoleic acid (18:2 $\omega 6)$, and stearic acid (18:0), comparable to those of plant oils used for biodiesel production. It has long been known that cultivation conditions affect the fatty acid profile (Woodbine, 1959). For example, in Rhodosporidium toruloides, growth on xylose rather than glucose altered the linoleic and linolenic acid proportions (Woodbine, 1959), and higher cultivation temperatures result in more saturated fatty acids (Bass and Hospodka, 1952). Temperature effects on fatty acid saturation were also seen in Rhodotorula glacialis (Amaretti, Raimondi, 2010). Production of desired fatty acids with optimal fuel properties such as cold flow and combustion properties and energy content must take these conditions into consideration.

Sitepu et al. (Sitepu, Sestric, 2013) cultured 69 yeast strains in a defined low nitrogen medium (Medium A (Suutari, Liukkonen, 1990)) for four days (Culture A), for seven days (Culture B), or for a total of seven days with a shift from low nitrogen to nitrogen-free medium at four days (Culture C). Total lipid was measured gravimetrically as described above. Fatty acid methyl esters were analyzed by GCFID (Yakes et al. , 2011). Fatty acid profiles were altered by the varied culture conditions, though the degree and type of alteration was very species and strain specific. For example, while two strains of Scheffersomyces stipitis exhibited a marked increase in oleic acid concentration from trace in Culture A to 
1147

1148

1149

1150

1151

1152

1153

1154

1155

1156

1157

1158

1159

1160

1161

1162

1163

1164

1165

1166

1167

1168

1169

1170

1171

1172

1173

1174

1175

1176

1177

1178

1179

1180

1181

1182

1183

1184

1185

1186

49-54\% of total fatty acids in Culture C, a strain of Leucosporidiella creatinivora exhibited a drop from $57 \%$ to less than $1 \%$.

\subsection{Effects of inhibitors on oil productivity}

Pretreated, hydrolyzed lignocellulosic biomass contains toxic compounds that may inhibit yeast growth and thus overall lipid productivity. Growth inhibitors include breakdown products of hemicellulose, such as acetic acid; products of the partial degradation of lignin, such as phenolic compounds; and furan derivatives such as furfural and HMF resulting from the degradation of pentoses and hexoses. Selection of an oleaginous yeast strain suitable for conversion of a given hydrolysate should take into consideration tolerance of the inhibitors present in that hydrolysate. The most notorious inhibitors of yeast productivity include: 5-(hydroxymethyl)furfural (HMF), furfural, acetic acid, formic acid, levulinic acid, vanillin, and p-benzaldehyde (Palmqvist and Hahn-Hagerdal, 2000, Palmqvist and Hahn-Hägerdal, 2000, Parawira and Tekere, 2011, Zha et al. , 2012, Zhang et al. , 2010).

The effects of inhibitors on yeast oil production has been examined (Chen et al. , 2009b, Hu, Zhao, 2009). For example, removal of inhibitors from rice straw hydrolysate by overliming followed by adsorption on Amberlite XAD-4 greatly improved lipid yield of oleaginous yeast T. fermentans from 1.7 to $11.5 \mathrm{~g} / \mathrm{L}$ (Huang, Zong, 2009a). Activated charcoal was demonstrated to be an effective, less costly method for detoxification (Huang, Chen, 2013b). Zhang et al. (Zhang, Zhu, 2010) identified a fungal strain, Amorphotheca resinae $\mathrm{ZN1}$, that could be used to detoxify pretreated lignocellulose, resulting in improved lipid production by oleaginous yeast (Huang, Wang, 2011b).

Rather than removing inhibitors, use of an oleaginous yeast strain that is naturally resistant to relevant inhibitors would be a more cost-effective strategy. In a comparison of 10 oleaginous yeast strains belonging to 5 oleaginous species, cell mass accumulation and lipid production were found to be inhibitor- and yeast strain-specific (Chen, Li, 2009b, Hu, Zhao, 2009). Acetic acid, formic acid, furfural and vanillin most strongly affected lipid production in these yeasts. One strain of T. cutaneum was shown to be particularly resistant to the inhibitors studied. In another study, Galafassi et al. (Galafassi, Cucchetti, 2012) demonstrated that a strain of Rhodotorula graminis could be cultivated on undetoxified corn stover hydrolysate, and produce $0.21 \mathrm{~g} \mathrm{lipid} / \mathrm{L} / \mathrm{h}$ and reach $34 \%$ oil w/w. Selection of an oleaginous yeast that is naturally resistant to the inhibitors, or that can inactivate the inhibitors, would reduce production costs significantly.

Characterization of a broad selection of yeast strains would enable selection of yeasts with desired combinations of properties. Sitepu et al. (Sitepu, Selby, 2014b) compared the inhibitor tolerance of a broad range of oleaginous yeast species. All 48 oleaginous yeast strains tested grew well in the presence of $0.5 \mathrm{~g} / \mathrm{L} 5$-(hydroxymethyl)furfural (HMF), but only seven could grow well in $1 \mathrm{~g} / \mathrm{L}$ furfural, and twelve in the presence of $2.5 \mathrm{~g} / \mathrm{L}$ acetic acid (selected results summarized in Table 6). This finding confirmed that furfural is a strong inhibitor of yeast growth, which is in agreement with Qi et al. (Qi, Kitahara, 2013). This study also emphasized the importance of examining multiple strains within a species. For example, two strains of Rhodosporidium babjevae exhibited very different levels of HMF tolerance.

\section{Pilot scale and demonstration scale production of yeast lipids}


Pilot and commercial production of yeast lipids for oleochemical or nutritional uses has been demonstrated multiple times over the past century. As discussed in Section 2.2, early efforts, particularly those in Germany during the first half of the 20th century, focused on high-oil yeasts as a source of nutritional lipids for human consumption (Lundin, 1950, Stanier, 1946, Woodbine, 1959). A high-fat paste made from the yeast Guehomyces pullulans (formerly called Endomycopsis vernalis) was produced commercially and used in and on baked goods (Lundin, 1950). A high-fat (25.3\%) nutritional yeast paste having a "pleasant, peanut-like taste" was produced at 10,000 liter-scale using the species Candida reukaufii (anamorph of Metschnikowia reukaufii) (described in (Koch, 1949, Koch, Thomas, 1949, Woodbine, 1959). In 1950, Lundin estimated that production of high-oil yeast cell mass for human consumption would cost between US $\$ 0.25$ and $\$ 0.55$ per kilogram. Due to the high cost, nutritional yeast oils were only produced during times of shortage or high cost of conventional oils.

In more recent years, there have been a few reports of pilot-scale production of oleaginous yeasts, such as cultivation of $200 \mathrm{~L}$ of Trichosporon oleaginosus (Bell and Davies, 1987) At the industrial level, demonstration-scale production of yeast biodiesel is yet to be reported, but industrial production of highvalue nutritional fatty acids such as DHA and EPA using genetically modified Yarrowia lipolytica is the subject of numerous patents (for example, (Damude, Gillies, 2011, Damude, Macool, 2009)). The large number of patent applications by Solazyme suggests imminent commercial production of yeast oil for food and chemicals (Franklin, Decker, 2011a, Franklin, Piechocki, 2011b, Trimbur, Im, 2012a, b).

\section{Conclusions: Areas of potential improvement}

A small number of oleaginous yeast species and strains have been utilized in the majority of recent publications, including Rhodosporidium toruloides, Rhodotorula glutinis, Lipomyces lipofera, Lipomyces starkeyi, Cryptococcus curvatus, Trichosporon pullulans and Yarrowia lipolytica. The expanding array of oleaginous yeast species and strains described in Section 3.1 will allow selection of a strain with suitable characteristics for utilization of different hydrolysates including sugar utilization, osmotolerance, inhibitor tolerance, and ability to grow without supplemented vitamins. Ability to accumulate high lipids at low $\mathrm{pH}$ would be valuable, as low $\mathrm{pH}$ can be used to discourage growth of contaminating bacteria.

1214 Some ideal characteristics of a lipid-producing yeast strain include:

- High oil accumulation

- High cell density

- Fast growth

- Complete, simultaneous utilization of all carbohydrates in the target hydrolysate

- Osmotolerance

- High tolerance of the inhibitors present in the target hydrolysate

- Growth independent of added vitamins

While most yeasts are harmless, it is important to note that some yeasts are pathogenic to humans, animals or plants. Of the oleaginous species in Table 3, some strains of Filobasidiella/Cryptococcus neoformans, Candida tropicalis, and several Trichosporon species are known human pathogens. Cryptococcus albidus has been isolated from various clinical sources, and has been known to cause infections in immunocompromised patients (de Castro et al. , 2005, Johnson et al. , 1998). Cryptococcus curvatus has been identified as the causative agent of myeloradiculitis in AIDS patients (Dromer et al. , 
1228

1229

1230

1231

1232

1233

1234

1235

1236

1237

1238

1239

1240

1241

1242

1243

1244

1245

1246

1247

1248

1249

1250

1251

1252

1253

1254

1255

1256

1257

1258

1259

1260

1261

1262

1263

1264

1265

1266

1267

1268

1995). Potential pathogenicity to humans, animals and plants should be taken into consideration before selecting yeasts for industrial applications.

Production of biodiesel, a bulk commodity, using oleaginous microbes has been the subject of research for many decades. However, excessive costs have prevented this technology from reaching the market. In addition to the strain and process improvements listed above, which are underway, other factors to be considered for a Life Cycle Analysis or Life Cycle Assessment to determine the economic feasibility of yeast biodiesel include the cost of producing lignocellulosic biomass hydrolysates, and transesterification of yeast TAGs to produce biodiesel. Tornqvist and Lundin performed a cost analysis for producing an edible high-oil yeast paste using $R$. toruloides grown on molasses in 1951 (Tornqvist and Lundin, 1951). Given that a recent yeast oil production cost estimate was US $\$ 3,000$ per tonne (Ratledge and Cohen, 2008), an economically viable process will require improvements in the cultivation and processing of yeast oils, as well as valorization of multiple coproducts as is common practice for plant oil processing.

Hydrolysate production improvements are underway, including dramatically lowered cellulase enzyme costs and decreased inhibitor levels in hydrolysates. Other higher-value oleochemical products such as nutritional polyunsaturated fatty acids, solvents, adhesives, lubricants, or platform chemicals that have a higher profit margin may become economically viable before biodiesel does. Additional strategies such as capturing multiple product streams from oleaginous yeasts such as vitamins, pigments, protein and carbohydrates may tip the balance towards economic viability.

\section{Acknowledgments}

Funded in part by Grant Number U01TW008160 from the NIH Fogarty International Center, the NIH Office of Dietary Supplements, the National Science Foundation and the Department of Energy. This project was supported by the USDA Agricultural Food Research Initiative of the National Food and Agriculture, USDA, Grant \#35621-04750. The content is solely the responsibility of the authors and does not necessarily represent the official views of the Fogarty International Center or the National Institutes of Health, the Office of Dietary Supplements, the National Science Foundation, the Department of Energy, or the Department of Agriculture. We would like to thank the Natural Sciences and Engineering Research Council (NSERC) of Canada for its support of BioFuelNet, through the Network Centres of Excellence (NCE) program. The authors gratefully acknowledge funding from the National Mexican Council of Science and Technology (CONACYT) Fellowship 291795 awarded to LAG. The authors are grateful to Gilbert Shama, Loughborough University, UK, for providing a copy of the 1946 Stanier report, and to Herman Phaff for preserving vintage literature related to yeast lipids. The authors are grateful to the anonymous reviewers, whose suggestions helped to improve the manuscript.

\section{Role of the funding source}

The funding sources did not play a role in study design; collection, analysis or interpretation of data; writing of the manuscript; or decision to submit this manuscript for publication. 
Figure 1. Conversion of triacylglycerides (TAG) to fatty acid methyl esters (FAMEs) plus glycerol by transesterification.

[To be reproduced in color on the Web only; black and white in print]

Figure 2. Lignocellulose structure, pretreatment and hydrolysis products. Pretreatment and hydrolysis of cellulose, hemicellulose and lignin produces a hydrolysate of complex composition. Some of the commonly produced compounds are shown including carbohydrates, phenolic compounds, furans, organic acids.

[To be reproduced in color on the Web only; black and white in print]

Figure 3. Fatty acid synthesis and accumulation pathways. The diagram describes the connection between fatty acid synthesis, triacylglycerol synthesis and lipid droplet formation. Abbreviations: ACC: Acetyl CoA carboxylase; ACL: ATP:citrate lyase; ACP: acyl carrier protein; AMPD: AMP deaminase; AT: acetyl CoA transacylase; CDP: cytidine diphosphate; CS: Citrate synthase; DAG: Diacylglycerol; DGAT: diacylglycerol acyl transferase; DH: $\beta$ hydroxyacyl-ACP dehydratase; ER: Endoplasmic reticulum; EAR: enoyl-ACP reductase; FAS II: Type II fatty acid synthase; G3PAT: glycerol 3 phosphate acyl transferase; ID: Isocitrate dehydrogenase; KR: $\beta$-ketoacyl-ACP reductase; KS: $\beta$-ketoacyl-ACP synthase; LD: Lipid droplet; LPA: lysophosphatidic acid; LPAT: lysophosphatIdic acid:acyl CoA transferase; MAG: Monoacylglycerol; MD; Malate dehydrogenase; ME: malic enzyme (cytosolic); ME 2: Malic enzyme (ER membrane, responsible for fatty acid desaturation); MPT: malonylpalmitoyl transacylase; NLD: Nascent lipid droplet; PA: phosphatidic acid; PAP: phosphatidic acid phosphatase; PL: phospholipid; PYC: Pyruvate decarboxylase; TAG: Triacylglyceride.

[To be reproduced in color on the Web only; black and white in print] 
Table 1. Relationship between Fatty acid structure and Biodiesel performance parameters (Knothe, 2005, 2008, Steen, Kang, 2010)(. Thus it has been proposed to select yeast that produce high amounts of oleic acid (Knothe, 2005) as potential candidates for biodiesel purposes, because this fatty acid best meets these criteria.

\begin{tabular}{lccccc}
\hline & $\begin{array}{c}\text { Cetane Number } \\
\text { (ignition quality: } \\
\text { greater is better) }\end{array}$ & $\begin{array}{c}\text { Melting } \\
\text { Point (lower } \\
\text { is better) }\end{array}$ & $\begin{array}{c}\text { Oxidative } \\
\text { Stability (more } \\
\text { stable is better) }\end{array}$ & $\begin{array}{c}\text { Kinematic Viscosity } \\
\text { (less viscous is } \\
\text { better) }\end{array}$ & $\begin{array}{c}\text { Heat of } \\
\text { combustion } \\
\text { (greater is } \\
\text { better) }\end{array}$ \\
\hline Chain length & Longer is better & $\begin{array}{c}\text { Shorter is } \\
\text { better }\end{array}$ & NR & Shorter is better & Longer is better \\
$\begin{array}{l}\text { Degree of } \\
\text { Unsaturation }\end{array}$ & Saturated is better & $\begin{array}{c}\text { Unsaturated is } \\
\text { better } \\
\text { Branching }\end{array}$ & Saturated is better & Unsaturated is better & NR \\
\hline
\end{tabular}

NR: Not relevant 
Table 2. Examples of units used in publications to describe production of lipid by oleaginous yeasts. Proposed standardized terms are shown in bold.

\begin{tabular}{|c|c|c|}
\hline $\begin{array}{c}\text { Lipid and cell mass production } \\
\text { measures }\end{array}$ & Definition & Units \\
\hline $\begin{array}{l}\text { Cell mass production } \\
\text { (also called cell mass titer or } \\
\text { biomass production in some } \\
\text { publications) }\end{array}$ & $\begin{array}{l}\text { Amount of dry microbial cell mass } \\
\text { produced relative to culture volume }\end{array}$ & $\mathrm{g}$ cell dry cell mass per liter culture \\
\hline $\begin{array}{l}\text { Cell mass yield } \\
\text { (also called biomass yield in } \\
\text { some publications) }\end{array}$ & $\begin{array}{l}\text { Ratio of cell mass produced to sugar } \\
\text { consumed }\end{array}$ & g yeast per g sugar consumed \\
\hline $\begin{array}{l}\text { Cell mass conversion } \\
\text { (also called biomass conversion, } \\
\text { yield coefficient or biomass yield } \\
\text { in some publications) }\end{array}$ & $\begin{array}{l}\text { Dry yeast cell mass produced } \\
\text { relative to mass of carbohydrate } \\
\text { consumed }\end{array}$ & $\begin{array}{l}\mathrm{g} \text { yeast per } 100 \mathrm{~g} \text { sugar used, or } \mathrm{g} \\
\text { yeast per } \mathrm{g} \text { sugar in media }\end{array}$ \\
\hline Lipid content & $\begin{array}{l}\text { Weight of extractable lipid relative } \\
\text { to weight of dry cell mass }\end{array}$ & $\begin{array}{l}\%(\mathrm{w} / \mathrm{w}) ; \mathrm{g} \text { lipid per } 100 \mathrm{~g} \text { yeast } \\
\text { (dry weight) }\end{array}$ \\
\hline $\begin{array}{l}\text { Lipid coefficient } \\
\text { (also called fat coefficient, lipid } \\
\text { yield, maximum yield, } \\
\text { conversion) }\end{array}$ & $\begin{array}{l}\text { Lipid produced relative to carbon } \\
\text { input or carbon consumed; } \\
\text { expressed as a percentage or ratio }\end{array}$ & $\begin{array}{l}\mathrm{g} \text { lipid per g or } 100 \mathrm{~g} \text { carbohydrate } \\
\text { consumed or per g or } 100 \mathrm{~g} \text { glucose } \\
\text { in initial media }\end{array}$ \\
\hline $\begin{array}{l}\text { Lipid output } \\
\text { (also called lipid yield in some } \\
\text { publications) }\end{array}$ & Lipid yield per volume of culture & $\mathrm{g}$ lipid per liter of culture \\
\hline $\begin{array}{l}\text { Lipid productivity } \\
\text { (also called lipid volumetric } \\
\text { productivity, productivity, or } \\
\text { lipid output) }\end{array}$ & Rate of oil production & $\begin{array}{l}\text { mass or volume lipid per volume } \\
\text { culture per time; examples include } \\
\text { grams lipid per liter per hour, grams } \\
\text { lipid per liter per day, or grams lipid } \\
\text { per } \mathrm{m}^{3} \text { per day for bioreactors, or } \\
\text { grams per } \mathrm{m}^{2} \text { per day for ponds, or } \\
\text { liters per hectare per year for } \\
\text { agricultural crops }\end{array}$ \\
\hline Specific rate of lipid formation & $\begin{array}{l}\text { Rate of lipid accumulation relative } \\
\text { to cell mass }\end{array}$ & $\mathrm{g}$ lipid per hour per g cells \\
\hline
\end{tabular}


Table 3. Oleaginous yeast species. Yeast species with a reported lipid content of $20 \%$ (v/v) or more are listed. An early citation of the lipid content is given. Species (a) Ascomycetous yeast species. (b) Basidiomycetous yeast species.

\begin{tabular}{|c|c|c|}
\hline Taxonomic placement & $\begin{array}{c}\text { Genus, species } \\
\text { (synomyms or anamorph) }\end{array}$ & Strain, \% oil, an early reference or our recent report \\
\hline Phylum Ascomycota & MYXOZYMA MELIBIOSI & UCDFST 52-87: 23\% (Sitepu, Sestric, 2013) \\
\hline Subphylum Saccharomycotina & Myxozyma udenii & NRRL Y-17387: $20.3 \%$ (B. Dien, manuscript in preparation) \\
\hline Class Saccharomycetes & Lipomyces lipofer (syn. Torulopsis lipofera) & NCYC, strain not given: $43 \%$ (Kleinzeller, 1944) \\
\hline \multirow{5}{*}{$\begin{array}{l}\text { Order Saccharomycetales } \\
\text { Family Lipomycetaceae }\end{array}$} & Lipomyces lipofer & CBS 944: 40\% (McElroy and Stewart, 1967) \\
\hline & Lipomyces tetrasporus (syn. Zygolipomyces lactosus) & IBPhM y-695: 66.5\% (Eroshin and Krylova, 1983) \\
\hline & Lipomyces starkeyi & Starkey strain 74: 62\% (Starkey, 1946) \\
\hline & Lipomyces doorenjongii & CBS 7542: 72.3\% (Oguri, Masaki, 2012) \\
\hline & Lipomyces kockii & CBS 7729: 77.8\% (Oguri, Masaki, 2012) \\
\hline \multirow[t]{3}{*}{ Family Metschnikowiaceae } & Kodamaea ohmeri (syn. Candida guilliermondii) & BY4-523: 53.28\% (Kitcha and Cheirsilp, 2011) \\
\hline & Metschnikowia pulcherrima (anamorph Candida pulcherrima) & J2-4: 30\% (Pan, Yang, 2009) \\
\hline & Metschnikowia gruessii (syn, Nectaromyce reukaufii) & (No strain ID): 34\% (Stanier, 1946) \\
\hline \multirow[t]{5}{*}{ Family Wickerhamomycetacaea } & $\begin{array}{l}\text { Cyberlindnera jadinii (syn. Candida utilis, Pichia jadinii, Candida } \\
\text { guilliermondii) }\end{array}$ & (na): 20 to $30 \%$ (Schmidt, 1947) \\
\hline & $\begin{array}{l}\text { Cyberlindnera jadinii (syn. Candida utilis, Pichia jadinii, Candida } \\
\text { guilliermondii) }\end{array}$ & Y-1289: 22\% (Jigami et al. , 1979) \\
\hline & Cyberlindnera saturnus (syn. Lindnera saturnus, Hansenula saturnus) & CBS 5761: 25\% (Boulton and Ratledge, 1981) \\
\hline & Candida freyschussii & DBVPG 6208: 32\% (Amaretti, Raimondi, 2012) \\
\hline & Wickerhamomyces ciferrii (syn. Hansenula ciferrii) & NRRL Y-1031: 22\% (Hopton and Woodbine, 1960) \\
\hline $\begin{array}{c}\text { Family Debaryomycetaceae } \\
\text { (Schwanniomyces clade) }\end{array}$ & Schwanniomyces occidentalis & (Strain not named): 23\% (Guerzoni et al. , 1985) \\
\hline $\begin{array}{l}\text { Family Debaryomycetaceae } \\
\text { (Candida fragi clade) }\end{array}$ & KURTZMANIELLA CLERIDARUM (syn. Candida cleridarum) & UCDFST 76-729.2: 33\% (Sitepu, Sestric, 2013) \\
\hline \multirow[t]{2}{*}{$\begin{array}{l}\text { Family Debaryomycetaceae } \\
\text { (Yamadazyma clade) }\end{array}$} & Candida diddensiae & $\begin{array}{l}\text { Moscow Technical Institute of Food Industry collection, strain 2: } 37 \% \\
\text { (Malkhas'ian et al., 1982) }\end{array}$ \\
\hline & Candida aff. tenuis & LEB-M3: 20.46 to $56.58 \%$ (Duarte and Paim de Andrade, 2013) \\
\hline $\begin{array}{l}\text { Family Debaryomycetacaea } \\
\text { (Lodderomyces-Spathaspora clade) }\end{array}$ & Candida tropicalis & (na): $23 \%$ (Andreevskaya and Zalashko, 1979) \\
\hline \multirow[t]{5}{*}{ Family Dipodascaceae } & Geotrichum fermentans (syn. Trichosporon fermentans) & IBPhM y-481: 19.50\% (Eroshin and Krylova, 1983) \\
\hline & Geotrichum histeridarum & CBS 9892: 33.77\% (Franklin, Decker, 2011a) \\
\hline & Magnusiomyces magnusii (syn. Endomyces magnusii) & (VKPM Y-261): 27\% (Zhelifonova et al. , 1983) \\
\hline & $\begin{array}{l}\text { Galactomyces candidus (anamorph Geotrichum candidum, syn. } \\
\text { Oospora lactis, Oidium) }\end{array}$ & "Group L": up to 50\% (Geffers, 1937) \\
\hline & Galactomyces pseudocandidus (syn. Geotrichum vulgare) & CBS 10073: 28.04\% (Franklin, Decker, 2011a) \\
\hline Family Saccharomycetaceae & Torulaspora delbrueckii & CBS 2924: 40\% (Franklin, Decker, 2011a) \\
\hline $\begin{array}{c}\text { Order Saccharomycetales } \\
\text { Family incertae sedis }\end{array}$ & Trigonopsis variabilis & CBS 1040: 20 to $43.7 \%$ (Sentheshanmuganathan and Nickerson, 1962) \\
\hline Family incertae sedis & Yarrowia lipolytica (syn. Candida lipolytica) & NRRL Y-1094: 37.6 to $54.8 \%$ (Bati et al. , 1984) \\
\hline
\end{tabular}




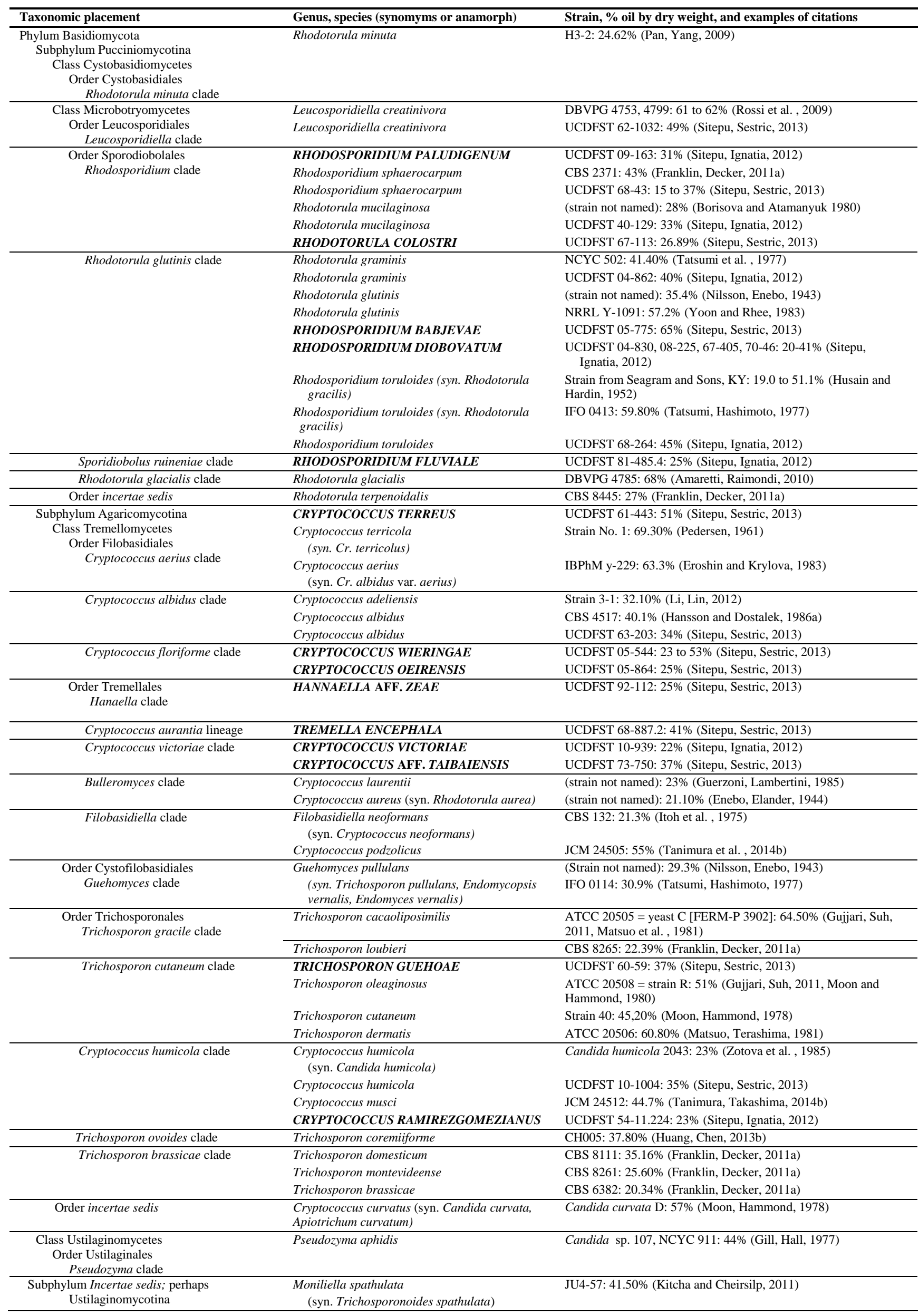


Table 4. Lipophilic dyes used for detecting intracellular lipids

\begin{tabular}{|c|c|c|c|c|}
\hline $\begin{array}{l}\text { Dye and condition } \\
\text { required for lipid } \\
\text { detection }\end{array}$ & Taxon and species tested & Instrument & $\begin{array}{l}\text { Reported advantage or } \\
\text { disadvantage }\end{array}$ & References \\
\hline $\begin{array}{l}\text { Green fluorescence dye } \\
\text { BODIPYTM 505/515 } \\
\text { (Invitrogen). Excitation } 450- \\
490 \mathrm{~nm} \text {, emission } 515 \mathrm{~nm} \text {. } \\
\text { Longer than } 30 \mathrm{~min} \text {, } \\
0.067 \mathrm{ug} / \mathrm{ml} \text {. }\end{array}$ & $\begin{array}{l}\text { Microalgae (Chlorella vulgaris, Dunaliella } \\
\text { primolecta, Chaetoceros calcitrans (Govender et } \\
\text { al. 2012), Ophiocytium maius Naegeli, } \\
\text { Chrysochromulina sp. (Cooper et al. 2010) }\end{array}$ & $\begin{array}{l}\text { Confocal scanning laser } \\
\text { microscopy }\end{array}$ & $\begin{array}{l}\text { Does not photobleach like Nile red, } \\
\text { does not accumulate in organelles } \\
\text { othr than lipid bodies }\end{array}$ & $\begin{array}{l}\text { (Cooper et al. , 2010, Govender } \\
\text { et al. , 2012) }\end{array}$ \\
\hline $\begin{array}{l}\text { BODIPY тм } 493 / 503 \\
\text { (Invitrogen). Excitation } 493 \\
\mathrm{~nm} \text {, emission } 500-530 \mathrm{~mm} \text {. }\end{array}$ & & Fluorescence microscope & & Inivitrogen, USA \\
\hline $\begin{array}{l}\text { Red fluorescence dye, Nile } \\
\text { red. Emax at } 5 \text { min after } \\
\text { NR addition, Emax } 488 \mathrm{~nm}\end{array}$ & $\begin{array}{l}\text { Yeast, fungi Lipomyces starkeyi IFO-10381, } \\
\text { Rhodosporidium toruloides IFO-0559, } \\
\text { Cryptococcus } \\
\text { curvatus IFO-1159, Mortierella isabellina } \\
\text { IFO-7884, Mortierella nana IFO-8794, } \\
\text { Mortierella } \\
\text { ramanniana var. angulispora IFO-8187. } \\
\text { Obtained from the Institute for Fermentation } \\
\text { (Osaka, } \\
\text { Japan) }\end{array}$ & Spectrofluorometer & $\begin{array}{l}\text { Strong bleaching of fluorescence. } \\
\text { Solvatochromism. } \\
\text { Broad excitation and emission } \\
\text { spectra. }\end{array}$ & $\begin{array}{l}\text { (Kimura, Yamaoka, 2004, } \\
\text { Radulovic, Knittelfelder, 2013) }\end{array}$ \\
\hline Nile red & $\begin{array}{l}\text { Microalgae (0.01-100ug/ml), excitation 480nm, } \\
\text { fluorescence intensity detected at 570-580nm: } \\
\text { several Chlorella and specific vulgaris (Huang et } \\
\text { al. 2009), Nannochloropsis sp. and Tetraselmis } \\
\text { sp. (Elsey et al. 2008) } \\
\text { Excitation 530nm, emission } 575 \text { nm for } \\
\text { Ankistrodesmus pseudobraunii UTEX LB1380, } \\
\text { Nannochloris sp. UTEX LB2291 the Provasoli- } \\
\text { Guillard, Chaetoceros lauderi CCMP 193; } \\
\text { Emiliania huxleyi CCMP 372; Crypthecodinium } \\
\text { cohnii CCMP 316, Rhodomonas salina CS } 24 ; \\
\text { Nannochloropsis sp. CS } 246 ; \text { Pavlova pinguis CS } \\
375 \text {, Chlorella zofingiensis. C. vulgaris LARB\#2, } \\
\text { Palmelococcus miniatus, Desmodesmus } \\
\text { quadricauda, Pseudochlorococcum sp. (Chen et } \\
\text { al. 2009) }\end{array}$ & Spectrofluorometer & $\begin{array}{l}\text { semi quantitative, concentration of } \\
\text { Nile red varies considerably } \\
\text { between different classes of algae } \\
\text { (Elsey et al. 2007) } \\
\text { 96-well plate is high throughput } \\
\text { (Chen et al. 2009) }\end{array}$ & $\begin{array}{l}\text { (Chen et al. , 2009a, Elsey, } \\
\text { Jameson, 2007, Huang et al., } \\
\text { 2009b) }\end{array}$ \\
\hline
\end{tabular}




\begin{tabular}{|c|c|c|c|c|}
\hline $\begin{array}{l}\text { Nile red. Neutral lipids } \\
\text { (excitation } 480-490 \mathrm{~nm}) \text {, } \\
\text { polar lipids }(510-560 \mathrm{~nm})\end{array}$ & Muscle cells, cultured peritoneal macrophages & $\begin{array}{l}\text { Fluorescence } \\
\text { microscopy, flow } \\
\text { cytofluorometry }\end{array}$ & $\begin{array}{l}\text { Very soluble in lipid and it does } \\
\text { not interact with any tissue } \\
\text { constituent }\end{array}$ & (Greenspan et al. , 1985) \\
\hline Nile red, Sudan black & Nematode: Chaenorhabditis elegants & $\begin{array}{l}\text { Transmission and freeze- } \\
\text { fracture electron } \\
\text { microscopy }\end{array}$ & Reviewed in Mak 2012 & \\
\hline $\begin{array}{l}\text { Sudan Black B with } \\
\text { Whatman No.1 filter paper }\end{array}$ & $\begin{array}{l}\text { Lipomyces starkeyi CBS } 6047 \text {, Cadida curvata D } \\
\text { (now called Cryptococcus curvatus) and } \\
\text { Trichosporon cutanemu } 40\end{array}$ & $\begin{array}{l}\text { Replica-printing } \\
\text { technique }\end{array}$ & $\begin{array}{l}\text { Did not work for pigmented yeasts } \\
\text { such as Rhodotorula, } \\
\text { Rhodosporidium }\end{array}$ & (Evans, Ratledge, 1985) \\
\hline $\begin{array}{l}\text { Sudan black B. Absorbance } \\
\text { at } 580 \mathrm{~nm}\end{array}$ & $\begin{array}{l}\text { Rhodotorula gracilis CFR } 1 \text { (Thakur 1989), } \\
\text { Rhodotorula glutinis (Dai et al. 2007) }\end{array}$ & & & $\begin{array}{l}\text { (Dai et al. , 2007, Thakur et al. } \\
\text { 1989) }\end{array}$ \\
\hline $\begin{array}{l}\text { Oil Red O, fluorescent dye. } \\
543 \text { or } 561 \mathrm{~nm} \text { excitation, } \\
550-570 \text { or } 570-650 \mathrm{~nm} \\
\text { emission. }\end{array}$ & Saccharomyces cerevisiae & Fluorescence microscopy & $\begin{array}{l}\text { Cell requires fixation because } \\
\text { impermeable }\end{array}$ & $\begin{array}{l}\text { (Adeyo et al. , 2011, Radulovic, } \\
\text { Knittelfelder, 2013) }\end{array}$ \\
\hline
\end{tabular}


Table 5. Recent reports of conversion of carbon sources and lignocellulosic hydrolysates to oil using oleaginous yeasts

\begin{tabular}{|c|c|c|}
\hline Lignocellulosic material & Oleaginous yeast species, strain & Reference \\
\hline Cassava starch hydrolysate & Rhodosporidium toruloides & (Wang et al. , 2012) \\
\hline Cassava starch hydrolysate & Rhodotorula mucilaginosa TJY15a & (Li et al. , 2010) \\
\hline $\begin{array}{l}\text { AFEX-pretreated corn stover } \\
\text { hydrolysate }\end{array}$ & $\begin{array}{l}\text { Cryptococcus humicola UCDFST } \\
\text { 10-1004, C. humicola UCDFST } \\
12-717, \text { C. laurentii UCDFST 12- } \\
803\end{array}$ & (Sitepu, Jin, 2014a) \\
\hline $\begin{array}{l}\text { Ionic liquid-pretreated corn stover } \\
\text { hydrolysate }\end{array}$ & Rhodosporidium toruloides Y4 & (Xie et al. , 2012) \\
\hline Corn stover hydrolysate & $\begin{array}{l}\text { Rhodotorula graminis DBVPG } \\
7021\end{array}$ & (Galafassi, Cucchetti, 2012) \\
\hline Corn cob acid hydrolysate & Trichosporon coremiiforme & (Huang, Chen, 2013a) \\
\hline Corn cob acid hydrolysate & Trichosporon dermatis & (Huang et al. , 2012a) \\
\hline Corncob acid hydrolysate & Trichosporon cutaneum $\mathrm{CH} 002$ & (Chen et al. , 2012b) \\
\hline Corn cob hydrolysate & $\begin{array}{l}\text { Trichosporon cutaneum ACCC } \\
20271\end{array}$ & (Gao, Cui, 2014) \\
\hline Pretreated biodetoxified corn stover & Trichosporon cutaneum $\mathrm{CX} 1$ & (Liu et al. , 2012a) \\
\hline $\begin{array}{l}\text { Food waste hydrolysate and municipal } \\
\text { waste water }\end{array}$ & $\begin{array}{l}\text { Cryptococcus curvatus ATCC } \\
\text { 20509, Yarrowia lipolytica ATCC } \\
\text { 20460, Rhodotorula glutinis } \\
\text { ATCC } 204091\end{array}$ & (Chi, Zheng, 2011) \\
\hline $\begin{array}{l}\text { Populus Euramevicana } C V \text { [sic] leaf } \\
\text { hydrolysate }\end{array}$ & Rhodotorula glutinis & (Tao et al. , 2010) \\
\hline Rice straw hydrolysate & $\begin{array}{l}\text { Geotrichum fermentans } \\
\text { (syn. Trichosporon fermentans) }\end{array}$ & (Huang, Zong, 2009a) \\
\hline Sugar cane bagasse hydrolysate & $\begin{array}{l}\text { Geotrichum fermentans } \\
\text { (syn. Trichosporon fermentans) }\end{array}$ & (Huang, Wu, 2012b) \\
\hline Sugar cane bagasse hydrolysate & Yarrowia lipolytica Po1g & (Tsigie et al. , 2011) \\
\hline Sweet potato vine hydrolysate & $\begin{array}{l}\text { Geotrichum fermentans } \\
\text { (syn. Trichosporon fermentans) }\end{array}$ & (Zhan et al. , 2013) \\
\hline Wheat straw hydrolysate & $\begin{array}{l}\text { Five common oleaginous yeast } \\
\text { species }\end{array}$ & (Yu et al. , 2011) \\
\hline
\end{tabular}


Table 6. Carbon source utilization, inhibitor tolerance by selected oleaginous yeast strains and species. Yeasts were cultivated in Yeast Nitrogen Base containing the indicated carbon source $(0.5 \%)$, or Yeast Nitrogen Base with glucose and the indicated inhibitor, or in Vitamin Free Media, as described (Sitepu, Selby, 2014b). Shades of grey indicate relative final turbidity after 10 days growth. D: delayed growth.

\begin{tabular}{|c|c|c|c|c|c|c|c|c|c|c|c|c|c|c|}
\hline \multirow[b]{2}{*}{ Yeast species } & & \multicolumn{9}{|c|}{ Carbon Sources } & \multicolumn{3}{|c|}{ Inhibitors } & \multirow[b]{2}{*}{$\begin{array}{c}\text { Vitamin } \\
\text { Free } \\
\text { Media }\end{array}$} \\
\hline & \begin{tabular}{|c|} 
UCDFST \\
ID\#
\end{tabular} & Glucose & $\begin{array}{c}\text { D- } \\
\text { Xylose }\end{array}$ & $\begin{array}{c}\mathrm{L}- \\
\text { Arabinose }\end{array}$ & Cellobiose & Mannose & Galactose & Rhamnose & Sucrose & $\begin{array}{c}\text { Galacturonic } \\
\text { Acid }\end{array}$ & $\begin{array}{l}\text { Furfural } \\
(0.5 \mathrm{~L} / \mathbf{L})\end{array}$ & $\begin{array}{c}\text { Acetic } \\
\text { Acid } \\
(2.5 \mathrm{~g} / \mathbf{L})\end{array}$ & $\begin{array}{l}\text { HMF } \\
(2 \mathrm{~g} / \mathbf{L})\end{array}$ & \\
\hline Candida aff. tropicalis & $10-1087$ & & & & & & & & & & & & & \\
\hline Cryptococcus curvatus & $76-559$ & & & & & & & & & & & & D & \\
\hline Cryptococcus laurentii & $12-803$ & & & & & & & & & & D & & D & \\
\hline Cryptococcus ramirezgomezianus & $54-11.224$ & & & & & & & & & & D & & D & \\
\hline Hannaella aff. zeae & $92-112$ & & & & & D & & D & & & & & D & \\
\hline Lipomyces lipofer & $78-19$ & D & & & & & & & D & & D & & D & \\
\hline Lipomyces starkeyi & $78-23$ & & & D & D & & & $\mathrm{D}$ & D & & & & D & \\
\hline Rhodotorula glutinis & $50-309$ & & & & D & & & & D & & & & & D \\
\hline Schwanniomyces occidentalis & $73-1$ & & & & & & & & & & & & & \\
\hline Trichosporon coremiiforme & $88-108.4$ & & & & & & & & & & & & & \\
\hline Trigonopsis variabilis & $75-19$ & & & & & & & & & & & & & \\
\hline Wickerhamomyces ciferii & $04-836$ & & & & D & & & & & & & & & \\
\hline Yarrowia lipolytica & $51-30$ & & & & & & & & & & & & & \\
\hline
\end{tabular}




\section{References Cited}

Adeyo O, Horn PJ, Lee S, Binns DD, Chandrahas A, Chapman KD, et al. The yeast lipin orthologue Pah1p is important for biogenesis of lipid droplets. The Journal of cell biology. 2011;192:1043-55.

Ageitos JM, Vallejo JA, Veiga-Crespo P, Villa TG. Oily yeasts as oleaginous cell factories. Applied microbiology and biotechnology. 2011;90:1219-27.

Alvira P, Tomás-Pejó E, Ballesteros M, Negro M. Pretreatment technologies for an efficient bioethanol production process based on enzymatic hydrolysis: a review. Bioresource Technology. 2010;101:4851-61.

Amaretti A, Raimondi S, Leonardi A, Rossi M. Candida freyschussii: an oleaginous yeast producing lipids from glycerol. Chemical Engineering Transactions. 2012;27:139-44.

Amaretti A, Raimondi S, Sala M, Roncaglia L, De Lucia M, Leonardi A, et al. Single cell oils of the cold-adapted oleaginous yeast Rhodotorula glacialis DBVPG 4785. Microbial Cell Factories. 2010;9:73.

Andreevskaya V, Zalashko M. Effect of addition of salts on growth and synthesis of lipid in yeasts cultured on peat oxidates. Prikladnaya Biokhimiya i Mikrobiologiya. 1979;15:522-7. Angerbauer C, Siebenhofer M, Mittelbach M, Guebitz G. Conversion of sewage sludge into lipids by Lipomyces starkeyi for biodiesel production. Bioresource Technology. 2008;99:30516.

Atabani A, Silitonga A, Badruddin I, Mahlia T, Masjuki H, Mekhilef S. A comprehensive review on biodiesel as an alternative energy resource and its characteristics. Renewable and Sustainable Energy Reviews. 2012;16:2070-93.

Augustyn O, Kick J. Differentiation of yeast species, and strains wtihin species, by cellular fatty acid analysis. 1. Application of an adapted technique to differentiate between strains of Saccharomyces cerevisiae. J Microbiol Meth. 1989;10:9-23.

Augustyn O, Kock J, Ferreira D. Differention between yeast species, and strains within a species, by cellular fatty acid analysis 5. A feasible technique? System Appl Micrbiol. 1992;15:105-15.

Banno I. Studies on the sexuality of Rhodotorula. The Journal of General and Applied Microbiology. 1967;13:167-96.

Barnett JA, Payne RW, Yarrow D. Yeasts: characteristics and identification. 3rd ed. Cambridge, UK: Cambridge University Press; 2000.

Bass A, Hospodka J. Biosynthesis of fats by yeast. II. Composition of fat at various temperatures. Chemicke' Listy. 1952;46:243.

Bati N, Hammond E, Glatz B. Biomodification of fats and oils: trials with Candida lipolytica. J Am Oil Chemists Soc. 1984;61:1743-6.

Beg Q, Kapoor M, Mahajan L, Hoondal G. Microbial xylanases and their industrial applications: a review. Applied microbiology and biotechnology. 2001;56:326-38.

Bell D, Davies R. Cell harvesting of oleaginous yeast by cross-flow filtration. Biotechnology and Bioengineering. 1987;29:1176-8. 
Beopoulos A, Cescut J, Haddouche R, Uribelarrea J-L, Molina-Jouve C, Nicaud J-M. Yarrowia lipolytica as a model for bio-oil production. Progress in Lipid Research. 2009;48:375-87.

Beopoulos A, Desfougeres T, Sabirova J, Nicaud J-M. Yarrowia lipolytica as a cell factory for oleochemical biotechnology. In: Timmis K, editor. Handbook of hydrocarbon and lipid microbiology. Berlin Heidelberg: Springer-Verlag; 2010.

Beopoulos A, Mrozova Z, Thevenieau F, Le Dall M-T, Hapala I, Papanikolaou S, et al. Control of lipid accumulation in the yeast Yarrowia lipolytica. Applied and Environmental Microbiology. 2008;74:7779-89.

Berg J, Tymoczko J, Stryer L. Biochemistry, 6th Edition. New York: McMillan; 2006.

Blagović B, Rupčić J, Mesarić M, Georgiú K, Marić V. Lipid composition of brewer's yeast. Food technol biotechnol. 2001;39:175-81.

Bligh E, Dyer WJ. A rapid method of total lipid extraction and purification. Canadian journal of biochemistry and physiology. 1959;37:911-7.

Bokulich N, Hwang C, Liu S, Boundy-Mills K, Mills D. Profiling the yeast communities of wine fermentations using terminal restriction fragment length polymorphism analysis. Am $\mathrm{J}$ Enol Vitic. 2011;63:185-94.

Bokulich NA. Next-generation approaches to the microbial ecology of food fermentations. Biochemistry and Molecurar Biology Reports. 2012;45:377-89.

Bokulich NA, Bamforth CW, Mills DA. Brewhouse-resident microbiota are responsible for multi-stage fermentation of american coolship ale. PLoS ONE. 2012a;7:e35507.

Bokulich NA, Joseph CL, Allen G, Benson AK, Mills DA. Next-generation sequencing reveals significant bacterial diversity of botrytized wine. PLoS ONE. 2012b;7:e36357.

Bokulich NA, Mills DA. Facility-Specific "House" Microbiome Drives Microbial Landscapes of Artisan Cheesemaking Plants. Applied and Environmental Microbiology. 2013;79:5214-23. Botha A, Kock J. Application of fatty acid profiles in the identification of yeast. International Journal of Food Microbiology. 1993;19:39-51.

Botham P, Ratledge C. A biochemical explanation for lipid accumulation in Candida 107 and other oleaginous micro-organisms. Journal of general microbiology. 1979;114:361-75. Boulton C, Ratledge C. Correlation of lipid accumulation in yeasts with possession of ATP:citrate lyase. Microbiology. 1981;127:169-76.

Boulton C, Ratledge C. Use of transition studies in continuous cultures of Lipomyces starkeyi, an oleaginous yeast, to investigate the physiology of lipid accumulation. Journal of general microbiology. 1983;129:2871-6.

Boundy-Mills K. Yeast culture collections of the world: meeting the needs of industrial researchers. Journal of Industrial Microbiology \& Biotechnology. 2012;39:673-80.

Brodie J, Zuccarello G, Hodkinson T, Parnell J, Waldren S. Systematics of the species-rich algae: red algal classification, phylogeny and speciation. 2007.

Brown C, Rose A. Fatty acid composition of Candida utilis as affected by growth temperature and dissolved-oxygen tension. J Bacteriol. 1969;99:371-8.

Chen W, Zhang C, Song L, Sommerfeld M, Hu Q. A high throughput Nile red method for quantitative measurement of neutral lipids in microalgae. Journal of Microbiological Methods. 2009a;77:41-7.

Chen X, Li Z, Zhang X, Hu F, Ryu D, Bao J. Screening of oleaginous yeast strains tolerant to lignocellulose degradation compounds. Appl Biochem Biotechnol. 2009b;159:591-604. 
Chen X-F, Huang C, Xiong L, Chen X-D, Chen Y, Ma L-L. Oil production on wastewaters after butanol fermentation by oleaginous yeast Trichosporon coremiiforme. Bioresource Technology. 2012a;118:594-7.

Chen X-f, Huang C, Xiong L, Ma L-1. Microbial oil production from corncob acid hydrolysate by Trichosporon cutaneum. Biotechnology letters. 2012b;34:1025-8.

Chi Z, Zheng Y, Jiang A, Chen S. Lipid production by culturing oleaginous yeast and algae with food waste and municipal wastewater in an integrated process. Applied biochemistry and biotechnology. 2011;165:442-53.

Chisti Y. Biodiesel from microalgae. Biotechnol Adv. 2007;25:294-306.

Choi S, Ryu D, Rhee J. Production of Microbial Lipid: Effects of Growth Rate and Oxygen on Lipid Synthesis and Fatty Acid Composition of Rhodotorula gracilis. Biotechnology and Bioengineering. 1982;XXIV:1165-72.

Cohen Z, Ratledge C. Single Cell Oils. Champaign, Illinois: AOCS Press; 2005.

Connor MR, Atsumi S. Synthetic biology guides biofuel production. Journal of Biomedicine and Biotechnology. 2010;2010.

Cooper C. Yeasts pathogenic to humans. In: Kurtzman CP, Fell J, Boekhout T, editors. The Yeasts: A Taxonomic Study. 5 ed. Amsterdam: Elsevier; 2011. p. 9-19.

Cooper MS, Hardin WR, Petersen TW, Cattolico RA. Visualizing "green oil" in live algal cells. Journal of Bioscience and Bioengineering. 2010;109:198-201.

Crew H. The Tragedy of Rudolf Diesel. Evanston: Northwestern University; 1963.

Czabany T, Wagner A, Zweytick D, Lohner K, Leitner E, Ingolic E, et al. Structural and biochemical properties of lipid particles from the yeast Saccharomyces cerevisiae. Journal of Biological Chemistry. 2008;283:17065-74.

Dai C, Tao J, Xie F, Dai Y, Zhao M. Biological generation from oleaginous yeast Rhodotorula glutinis with xylose assimilating capacity. African Journal of Biotechnology. 2007;6:2130-4.

Damm H. A new biochemical fat synthesis. Chem Ztg. 1943;67:47-9.

Damude H, Gillies P, Macool D, Picataggio S, Walters Pollak D, Ragghlanti J, et al. High eicosapentaenoic acid producing strains of Yarrowia lipolytica. In: Patent US, editor. United States2011.

Damude H, Macool D, Picataggio S, Ragghlanti J, Selp J, Xue Z, et al. Docosahexaenoic acid producing strains of Yarrowia lipolytica. In: Patent US, editor. United States: E. I. du Pont de Nemours and Company; 2009.

Davis R, Aden A, Pienkos PT. Techno-economic analysis of autotrophic microalgae for fuel production. Applied Energy. 2011;88:3524-31.

de Castro LEF, Al Sarraf O, Lally JM, Sandoval HP, Solomon KD, Vroman DT. Cryptococcus albidus keratitis after corneal transplantation. Cornea. 2005;24:882-3.

Dickson RC, Lester RL. Sphingolipid functions in Saccharomyces cerevisiae. Biochimica et Biophysica Acta (BBA)-Molecular and Cell Biology of Lipids. 2002;1583:13-25.

Dijkerman R, Bhansing DC, Op den Camp HJ, van der Drift C, Vogels GD. Degradation of structural polysaccharides by the plant cell-wall degrading enzyme system from anaerobic fungi: an application study. Enzyme and microbial technology. 1997;21:130-6.

Dromer F, Moulignier A, Dupont B, Gueho E, Beadrimont M, Improvisi L, et al.

Myeloradiculitis due to Cryptococcus curvatus in AIDS. Aids. 1995;9:395-6.

Duarte S, Paim de Andrade C. Exploration of brazilian biodiversity and selection of a new oleaginous yeast strain cultivated in raw glycerol. Bioresource Technology. 2013; In press:I. Dunn C. Food Yeast. Wallerstein Laboratories Communications. 1952;40:61-79. 
Easterling ER, French WT, Hernandez R, Licha M. The effect of glycerol as a sole and secondary substrate on the growth and fatty acid composition of Rhodotorula glutinis. Bioresource Technology. 2009;100:356-61.

Eckelberry ND, Green MP, Fraser SA. Systems, apparatuses, and methods for extracting nonpolar lipids from an aqueous algae slurry and lipids produced therefrom. Google Patents; 2010. El Manyawi I, Wogerbauer M. Identification of yeast species by fatty acid profiling as measured by gas-liquid chromatography. J Chromatogr B Biomed Sci Appl. 2000;742:13-24. Elle IC, Olsen LCB, Pultz D, Rødkær SV, Færgeman NJ. Something worth dyeing for: Molecular tools for the dissection of lipid metabolism in Caenorhabditis elegans. FEBS Letters. 2010;584:2183-93.

Elsey D, Jameson D, Raleigh B, Cooney MJ. Fluorescent measurement of microalgal neutral lipids. Journal of Microbiological Methods. 2007;68:639-42.

Enebo L, Anderson L, Lundin H. Microbiological fat synthesis by means of Rhodotorula yeast. Archives of biochemistry. 1946;11:383.

Enebo L, Elander M, Berg F, Lundin H, Nilsson R, Myrbäck K. Mikrobielle Fettsynthese durch Lufthefezuchtung von Rhodotorulaarten. I V A 1944;6:1.

Eroshin V, Krylova N. Efficiency of lipid synthesis by yeasts. Biotechnology and Bioengineering. 1983;XXV:1693-700.

Evans C, Ratledge C. Biochemical activities during lipid accumulation in Candida curvata. Lipids. 1983;18:630-5.

Evans C, Ratledge C. Effect of nitrogen source on lipid accumulation in oleaginous yeasts. J Gen Microbiol. 1984;130:1693-704.

Evans CT, Ratledge C, Gilbert SC. A rapid screening method for lipid-accumulating yeast using a replica-printing technique. Journal of Microbiological Methods. 1985;4:203-10. Evans CT, Scragg AH, Ratledge C. A Comparative Study of Citrate Efflux from Mitochondria of Oleaginous and Non - oleaginous Yeasts. European Journal of Biochemistry.

1983;130:195-204.

Fink H, Brackmann C, Enejder A. 18. Imaging Lipid Metabolism in L 'aenornabditis elegans and Other Model Organisms. Coherent Raman Scattering Microscopy. 2012;1:405.

Firestone D. Physical and chemical characteristics of oils, fats, and waxes: AOCS Press Champaign; 2006.

Fleet G. Yeast spoilage of foods and beverages. In: Kurtzman CP, Fell J, Boekhout T, editors. The Yeasts: A Taxonomic Study. 5 ed. Amsterdam: Elsevier; 2011. p. 53-63.

Folch J, Lees M, Sloane-Stanley G. A simple method for the isolation and purification of total lipids from animal tissues. J Biol chem. 1957;226:497-509.

Food and Agriculture Organization of the United Nations. FAOSTAT, http://faostat.fao.org, accessed 6 November 2013. 2009.

Franklin S, Decker SM, Wee J. Fuel And Chemical Production From Oleaginous Yeast. Google Patents; 2011a.

Franklin S, Piechocki J, Norris L, Decker S, Wee J, Zdanis D. Oleaginous yeast food compositions. In: USPTO, editor. US: Solazyme, Inc.; $2011 \mathrm{~b}$.

Frenkel R. Regulation and physiological functions of malic enzymes. Current topics in cellular regulation. 1975;9:157.

Fritsch H, Beevers H. ATP Citrate Lyase from Germinating Castor Bean Endosperm Localization and some Properties. Plant physiology. 1979;63:687-91. 
Gadanho M, Sampaio J, Spencer-Martins I. Polyphasic taxonomy of the basidiomycetous yeast genus Rhodosporidium: R. azoricum sp. nov. Canadian journal of microbiology. 2001;47:21321.

Gadanho M, Sampaio JP. Polyphasic taxonomy of the basidiomycetous yeast genus Rhodotorula: Rh. glutinis sensu stricto and Rh. dairenensis comb. nov. FEMS Yeast Research. 2002;2:47-58.

Galafassi S, Cucchetti D, Pizza F, Franzosi G, Bianchi D, Compagno C. Lipid production for second generation biodiesel by the oleaginous yeast Rhodotorula graminis. Bioresour Technol. 2012;111:398-403.

Gao Q, Cui Z, Zhang J, Bao J. Lipid fermentation of corncob residues hydrolysate by oleaginous yeast Trichosporon cutaneum. Bioresource Technology. 2014;152:552-6.

Garay L, Boundy-Mills K, German J. Accumulation of high value lipids in single cell microorganisms: A mechanistic approach and future perspectives. J Agric Food Chem. 2014;62:2709-27.

Geffers H. Untersnehungen uber das Fettbildungsvermogen bei Pilzen der Gattung Oospora Wallroth (em. Sacc.). Archiv fur Mikrobiologie. 1937;8:66-98.

Gill C, Hall J, Ratledge C. Lipid accumulation in an oleaginous yeast (Candida 107) growing on glucose in single-stage continuous culture. Applied and Environmental Microbiology.

1977;33:231-9.

Gírio F, Fonseca C, Carvalheiro F, Duarte L, Marques S, Bogel-Łukasik R. Hemicelluloses for fuel ethanol: a review. Bioresource Technology. 2010;101:4775-800.

Goldberg I. Organisms and Substrates. Single Cell Protein: Springer; 1985. p. 11-66.

Gong Z, Wang Q, Shen H, Hu C, Jin G, Zongbao K. Co-fermentation of cellobiose and xylose by Lipomyces starkeyi for lipid production. Bioresour Technol. 2012;117:20-4.

Govender T, Ramanna L, Rawat I, Bux F. BODIPY staining, an alternative to the Nile Red fluorescence method for the evaluation of intracellular lipids in microalgae. Bioresource Technology. 2012;114:507-11.

Green M, Eckelberry N, Fraser S, Goodall B. Systems, methods and apparatuses for dewatering, flocculating and harvesting algae cells. WO Patent 2,012,054,404; 2012. Greenspan P, Mayer EP, Fowler SD. Nile red: a selective fluorescent stain for intracellular lipid droplets. The Journal of Cell Biology. 1985;100:965-73.

Griffiths MJ, Harrison ST. Lipid productivity as a key characteristic for choosing algal species for biodiesel production. Journal of Applied Phycology. 2009;21:493-507.

Guerzoni M, Lambertini P, Lercker G, Marchetti R. Technological potential of some starch degrading yeasts. Starch. 1985;37:52-7.

Guiry M, Cunningham E. Photoperiodic and temperature responses in the reproduction of north-eastern Atlantic Gigartina acicularis (Rhodophyta: Gigartinales). Phycologia.

1984;23:357-67.

Gujjari P, Suh S-O, Coumes K, Zhou J. Characterization of oleaginous yeasts revealed two novel species: Trichosporon cacaoliposimilis sp. nov. and Trichosporon oleaginousus sp. nov. Mycologia. 2011;103:1110-8.

Hansson L, Dostalek M. Effect of culture conditions on fatty acid composition on lipids produced by the yeast Cryptococcus albidus var. albidus. J Am Oil Chemists Soc. 1986a;63:1179-84.

Hansson L, Dostalek M. Influence of cultivation conditions on lipid production by Cryptococcus albidus. Appl Microbiol Biotechnol. 1986b;24:12-8. 
Hassan M, Blanc PJ, Granger L-M, Pareilleux A, Goma G. Lipid production by an unsaturated fatty acid auxotroph of the oleaginous yeast Apiotrichum curvatum grown in single-stage continuous culture. Applied microbiology and biotechnology. 1993;40:483-8.

Henderson C, Lozada-Contreras M, Jiranek V, Longo M, Block D. Ethanol production and maximum cell growth are highly correlated with membrane lipid composition during fermentation as determied by lipidomic analysis of 22 Saccharomyces cerevisiae strains. Appl Environ Microbiol. 2013a;79:91-104.

Henderson CM, Lozada-Contreras M, Jiranek V, Longo ML, Block DE. Lipidomic analysis of 22 Saccharomyces cerevisiae strains indicates that ethanol production and maximum cell growth are highly correlated with membrane lipid composition during fermentation. Applied and Environmental Microbiology. 2012.

Henderson CM, Lozada-Contreras M, Naravane Y, Longo ML, Block DE. Analysis of major phospholipid species and ergosterol in fermenting industrial yeast strains using atmospheric pressure ionization ion-trap mass spectrometry. Journal of Agricultural and Food Chemistry. 2011;59:12761-70.

Henderson CM, Zeno WF, Lerno LA, Longo ML, Block DE. Fermentation temperature modulates phosphatidylethanolamine and phosphatidylinositol levels in the cell membrane of Saccharomyces cerevisiae. Applied and Environmental Microbiology. 2013b;79:5345-56. Hesse A. Industrial Biosyntheses: Part I. Fats. Advances in Enzymology and Related Areas of Molecular Biology, Volume 9. 1949:653-704.

Hibbett DS, Taylor JW. Fungal systematics: is a new age of enlightenment at hand? Nature Reviews Microbiology. 2013;11:129-33.

Hopton J, Woodbine M. Fat synthesis by yeasts. I. A comparative assessment of Hansenula species. J Appl Bacteriol. 1960;23:283-90.

Hu C, Wu S, Wang Q, Jin G, Shen H, Zhao Z. Simultaneous utilization of glucose and xylose for lipid production by Trichosporon cutaneum. Biotechnology for Biofuels. 2011;4:25. $\mathrm{Hu} \mathrm{C}$, Zhao X, Zhao J, Wu S, Zongbao K. Effects of biomass hydrolysis by-products on oleaginous yeast Rhodosporidium toruloides. Bioresource Technology. 2009;100:4843-7. Huang C, Chen X-f, Xiong L, Chen X-d, Ma L-l. Oil production by the yeast Trichosporon dermatis cultured in enzymatic hydrolysates of corncobs. Bioresource Technology.

2012a;110:711-4.

Huang C, Chen X-F, Xiong L, Chen X-D, Ma L-L, Chen Y. Single cell oil production from low-cost substrates: The possibility and potential of its industrialization. Biotechnology Advances. 2013a;31:129-39.

Huang C, Chen X-F, Xiong L, Yang X-Y, Chen X-D, Ma L-L, et al. Microbial oil production from corncob acid hydrolysate by oleaginous yeast Trichosporon coremiiforme. Biomass and Bioenergy. 2013b;49:273-8.

Huang C, Wu H, Li R-F, Zong M-H. Improving lipid production from bagasse hydrolysate with Trichosporon fermentans by response surface methodology. New Biotechnology. 2012b;29:372-8.

Huang C, Wu H, Liu Q-p, Li Y-y, Zong M-h. Effects of aldehydes on the growth and lipid accumulation of oleaginous yeast Trichosporon fermentans. Journal of agricultural and food chemistry. 2011a;59:4606-13.

Huang C, Wu H, Liu Z, Cai J, Lou W, Zong M. Effect of organic acids on the growth and lipid accumulation of oleaginous yeast Trichosporon fermentans. Biotechnol Biofuels. 2012c;5. 
Huang C, Zong M-H, Wu H, Liu Q-P. Microbial oil production from rice straw hydrolysate by Trichosporon fermentans. Bioresource Technology. 2009a;100:4535-8.

Huang G-H, Chen G, Chen F. Rapid screening method for lipid production in alga based on Nile red fluorescence. Biomass and Bioenergy. 2009b;33:1386-92.

Huang X, Wang Y, Liu W, Bao J. Biological removal of inhibitors leads to the improved lipid production in the lipid fermentation of corn stover hydrolysate by Trichosporon cutaneum.

Bioresource Technology. 2011b;102:9705-9.

Hui Y. Bailey's Industrial Oil and Fat Products. New York: John Wiley and Sons; 1996.

Hunter K, Rose AH. Lipid composition of Saccharomyces cerevisiae as influenced by growth temperature. Biochimica et Biophysica Acta (BBA)-Lipids and Lipid Metabolism.

1972;260:639-53.

Husain S, Hardin M. Influence of carbohydrate and nitrogen sources upon lipid production by certain yeasts. J Food Sci. 1952;17:60-6.

Itoh T, Waki H, Kaneko H. Changes in lipid composition with growth phase of Cryptococcus neoformans. Agr Biol Chem. 1975;39:2365-71.

Jacob Z. Yeast lipid biotechnology. Advances in Applied Microbiology. 1993;39:185-.

Jeffery J, Kock J, Botha A, Coetzee D, Botes P. The value of lipid composition in the taxonomy of the Schizosaccharomycetales. Antonie van Leeuwenhoek. 1997;72:327-35. Jigami Y, Suzuki O, Nakasato S. Comparison of lipid composition of Candida guilliermondii grown on glucose, ethanol and methanol as the sole carbon source. Lipids. 1979;14:937-42. Johnson E, Echevarri-Erasun C. Yeast biotechnology. In: Kurtzman CP, Fell J, Boekhout T, editors. The Yeasts: A Taxonomic Study. 5 ed. Amsterdam: Elsevier; 2011. p. 21-44.

Johnson L, Bradley SF, Kauffman CA. Fungaemia due to Cryptococcus laurentii and a review of non - neoformans cryptococcaemia. Mycoses. 1998;41:277-80.

Kalscheuer R, Stolting T, Steinbuchel A. Microdiesel: Escherichia coli engineered for fuel production. Microbiology. 2006;152:2529-36.

Kamisaka Y. Preparation of Oleaginous Yeast by Genetic Modification and Its Potential Applications. Biocatalysis and Biomolecular Engineering. 2010:57-65.

Kaneko H, Hosohara M, Tanaka M, Itoh T. Lipid Composition of 30 Species of Yeast. Lipids. 1976;11:837-44.

Kates M, Baxter R. Lipid composition of mesophilic and psychrophilic yeasts (Candida species) as influenced by environmental temperature. Canadian Journal of Biochemistry and Physiology. 1962;40:1213-27.

Kates M, Paradis M. Phospholipid desaturation in Candida lipolytica as a function of temperature and growth. Canadian Journal of Biochemistry. 1973;51:184-97.

Kessell R. Fatty acids of Rhodotorula gracilis: fat production in submerged culture and the particular effect of pH value. Journal of Applied Microbiology. 1968;31:220-31.

Kimura K, Yamaoka M, Kamisaka Y. Rapid estimation of lipids in oleaginous fungi and yeasts using Nile red fluorescence. J Microbiol Meth. 2004;56:331-8.

Kitcha S, Cheirsilp B. Screening of oleaginous yeasts and optimization for lipid production using crude glycerol as a carbon source. Energy Procedia. 2011;9:274-82.

Kleinzeller A. Fat formation in Torulopsis lipofera. Biochemical Journal. 1944;38:479-92.

Knothe G. Dependence of biodiesel fuel properties on the structure of fatty acid alkyl esters.

Fuel processing technology. 2005;86:1059-70.

Knothe G. "Designer" Biodiesel: Optimizing Fatty Ester Composition to Improve Fuel

Properties. Energy \& Fuels. 2008;22:1358-64. 
Koch R. Dtsch Gesundheitswes. 1949;4:1353.

Koch R, Thomas F, Bruchman E. Branntweinwirtschaft. 1949;3:65.

Kock J, Lategan P, Botes P, Viljoen B. Developing a rapid statistical identification process for different yeast species. Journal of Microbiological Methods. 1985;4:147-54.

Kornacker MS, Lowenstein J. Citrate and the conversion of carbohydrate in fat. The activities of citrate-cleavage enzyme and acetate thiokinase in livers of starved and re-fed rats. Biochem J. 1965;94:209-15.

Kraisintu P, Yongmanitchai W, Limtong S. Selection and optimization for lipid production of a newly isolated oleaginous yeast, Rhodosporidium toruloides DMKU3-TK16. Kasetsart J (Nat Sci). 2010;44:436-45.

Kumar S, Kushwaha H, Kumar Bachhawat A, Singh Raghava G, Ganesan K. Genome sequence of the oleaginous red yeast Rhodosporidium toruloides MTCC 457. Eukaryotic Cell. 2012;11:1083-4.

Kurtzman C, Fell J, Boekhout T. The Yeasts: A Taxonomic Study. 5th ed. Amsterdam: Elsevier; 2011a.

Kurtzman CP, Fell J, Boekhout T. Chapter 1. Definition, classification and nomenclature of the yeasts. In: Kurtzman C, Fell J, Boekhout T, editors. The Yeasts: A Taxonomic Study.

Amsterdam: Elsevier; 2011b. p. 3-5.

Kurtzman CP, Fell JW. The Yeasts: A Taxonomic Study. 4th ed. Amsterdam, The Netherlands: Elsevier Science B.V.; 2000.

Kurtzman CP, Smith M. Chapter 95. Myxozyma van der Walt, Weijman \& von Arx. In:

Kurtzman CP, Fell J, Boekhout T, editors. The Yeasts: A Taxonomic Study. Amsterdam: Elsevier; 2011. p. 1303-12.

Leiva-Candia D, Pinzi S, Redel-Macías M, Koutinas A, Webb C, Dorado M. The potential for agro-industrial waste utilization using oleaginous yeast for the production of biodiesel. Fuel. 2014;123:33-42.

Li M, Liu G-L, Chi Z, Chi Z-M. Single cell oil production from hydrolysate of cassava starch by marine-derived yeast Rhodotorula mucilaginosa TJY15a. Biomass and Bioenergy. 2010;34:101-7.

Li Q, Du W, Dehua L. Perspectives of microbial oils for biodiesel production. Appl Microbiol Biotechnol. 2008;80:749-56.

Li S, Lin Q, Li X, Xu H, Yang Y, Quiao D, et al. Biodiversity of the oleaginous microorganisms in Tibetan Plateau. Braz J Microbiol. 2012;43:627-34.

Liang M-H, Jiang J-G. Advancing oleaginous microorganisms to produce lipid via metabolic engineering technology. Progress in Lipid Research. 2013.

Lindner P. Das Problem der biologischen Fettbildung und Fettgewinnung. Angewandte Chemie. 1922;35:110-4.

Liu B, Zhao Z. Biodiesel production by direct methanolysis of oleaginous microbial biomass. J Chem Technol Biotechnol. 2007;82:775-80.

Liu H, Zhao X, Wang F, Jiang X, Zhang S, Ye M, et al. The proteome analysis of oleaginous yeast Lipomyces starkeyi. FEMS Yeast Res. 2011;11:42-51.

Liu H, Zhao X, Wang F, Li Y, Jiang X, Ye M, et al. Comparative proteomic analysis of Rhodosporidium toruloides during lipid accumulation. Yeast. 2009;26:553-66.

Liu L, Redden H, Alper HS. Frontiers of yeast metabolic engineering: diversifying beyond ethanol and Saccharomyces. Current opinion in biotechnology. 2013. 
Liu W, Wang Y, Yu Z, Bao J. Simultaneous saccharification and microbial lipid fermentation of corn stover by oleaginous yeast Trichosporon cutaneum. Bioresour Technol. 2012a;118:138.

Liu W, Wang Y, Yu Z, Bao J. Simultaneous saccharification and microbial lipid fermentation of corn stover by oleaginous yeast $<\mathrm{i}>$ Trichosporon cutaneum $</ \mathrm{i}>$. Bioresource Technology. 2012b;118:13-8.

Liu Z, Gao Y, Chen J, Imanaka T, Bao J, Hua Q. Analysis of Metabolic Fluxes for Better Understanding of Mechanisms Related to Lipid Accumulation in Oleaginous Yeast Trichosporon cutaneum. Bioresource Technology. 2012c.

Lodder J, Kreger-van Rij NJW. The Yeasts: A Taxonomic Study. First ed. Amsterdam: NorthHolland Publishing Company; 1952.

Lösel D. Chapter 10. Fungal lipids. In: Ratledge C, Wilkinson S, editors. Microbial Lipids, vol 1. London: Academic Press, Harcourt Brace Jovanovich; 1988. p. 699-806.

Lundin H. Fat synthesis by micro-organisms and its possible applications in industry. Journal of the Institute of Brewing. 1950;56:17-28.

Malkhas'ian S, Nechaev A, Gavrilova N, Zotova E, Doronina O. Group and fatty acid composition of the lipids in yeasts of the genus Candida. Prikladnaia Biokhimiia i Mikrobiologiia. 1982;18:621-9.

Matsuo T, Terashima M, Hasimoto Y, Hasida W. Method for producing cacao butter substitute. In: USPTO, editor. USA: Fuji Oil Company, Ltd (Osaka, Japan); 1981.

McElroy F, Stewart H. The lipids of Lipomyces lipofer. Canadian Journal of Biochemistry. 1967;45:171-8.

McMurrough I, Rose A. Effects of temperature variation on the fatty acid composition of a psychrophilic Candida species. Journal of Bacteriology. 1973;114:451.

McNeill J, Barrie F, Buck W, Demoulin V, Greuter W, Hawksworth D, et al. International code of nomenclature for algae, fungi and plants (Melbourne Code). Regnum Vegetabile 154 ed. Köeningstein, Germany: Koeltz Scientific Books; 2012.

Meesters P, Huijberts G, Eggink G. High-cell-density cultivation of the lipid accumulating yeast Cryptococcus curvatus using glycerol as a carbon source. Applied microbiology and biotechnology. 1996;45:575-9.

Melo R, D'Avila H, Bozza P, Weller P. Imaging lipid bodies within leucocytes with different light microscopy techniques. In: Chiarini-Garcia H, Melo R, editors. Light Microscopy: Methods in Molecular Biology 669: Springer Science+Business Media, LLC; 2011. Meng X, Yang J, Xu X, Zhang L, Nie Q, Xian M. Biodiesel production from oleaginous microorganisms. Renewable Energy. 2009;34:1-5.

Miao X, Wu Q. Biodiesel production from heterotrophic microalgal oil. Bioresour Technol. 2006;97:841-6.

Miller J, Webb N. Isolation of yeasts from soil with the aid of acid, rose bengal, and oxgall. Soil Sci. 1954;77:197-204.

Mlíčková K, Luo Y, d'Andrea S, Peč P, Chardot T, Nicaud J-M. Acyl-CoA oxidase, a key step for lipid accumulation in the yeast Yarrowia lipolytica. Journal of Molecular Catalysis B: Enzymatic. 2004;28:81-5.

Mondello L, Casilli A, Tranchida PQ, Costa R, Chiofalo B, Dugo P, et al. Evaluation of fast gas chromatography and gas chromatography-mass spectrometry in the analysis of lipids. Journal of Chromatography A. 2004;1035:237-47. 
Moon N, Hammond E. Process for converting whey permeate to oil-containing yeast In: USPTO, editor. USA: Iowa State University Research Foundation, Inc. (Ames, IA) 1980. Moon N, Hammond E, Glatz B. Conversion of cheese whey and whey permeate to oil and single-cell protein. J Dairy Sci. 1978;61:1537-47.

Mosier N, Wyman C, Dale B, Elander R, Lee YY, Holtzapple M, et al. Features of promising technologies for pretreatment of lignocellulosic biomass. Bioresource Technology.

2005;96:673-86.

Murphy DJ. The dynamic roles of intracellular lipid droplets: from archaea to mammals.

Protoplasma. 2012;249:541-85.

Nageli C, Loew O. Ueber die chemische Zysammensetzung der Hefe. Justus Liebigs Annalen der Chemis. 1878;193:322-48.

Nilsson R, Enebo L, Lundin H, Myrback K. Mikrobielle fettsynthese unter Verwendung von Rhodotorula glutinis nach dem Lufthefeverfahren (Microbial synthesis of fat with Rhodotorula glutinis). Svensk Kemisk Tidskrift. 1943;55:41.

Nuñez A, Ashby R, Foglia TA, Solaiman DK. LC/MS analysis and lipase modification of the sophorolipids produced by Rhodotorula bogoriensis**. Biotechnology letters. 2004;26:1087-

93.

Oguri E, Masaki K, Naganuma T, Iefuji H. Phylogenetic and biochemical characterization of the oil-producing yeast Lipomyces starkeyi. Antonie van Leeuwenhoek. 2012;101:359-68.

Palmqvist E, Hahn-Hagerdal B. Fermentation of lignocellulosic hydrolysates. I: inhibition and detoxification. Bioresource Technology. 2000;74:17-24.

Palmqvist E, Hahn-Hägerdal B. Fermentation of lignocellulosic hydrolysates. II: inhibitors and mechanisms of inhibition. Bioresource Technology. 2000;74:25-33.

Pan L-X, Yang D-F, Shao L, Li W, Chen G-G, Liang Z-Q. Isolation of the oleaginous yeasts from the soil and studies of their lipid-producing capacities. Food Technol Biotechnol. 2009;47:215-20.

Papanikolaou S, Aggelis G. Lipids of oleaginous yeasts. Part I: Biochemistry of single cell oil production. Eur J Lipid Sci Technol. 2011;113:1031-51.

Parawira W, Tekere M. Biotechnological strategies to overcome inhibitors in lignocellulose hydrolysates for ethanol production: review. Critical reviews in biotechnology. 2011;31:20-31. Pedersen T. Lipid formation in Cryptococcus terricolus. I. Nitrogen nutrition and lipid formation. Acta Chem Scand. 1961;15:651-62.

Pedersen T. Lipid formation in Cryptococcus terricolus. III. Extraction and purification of lipids. . Acta Chem Scand. 1962;16:374-82.

Piskur M. Review of literature on fats, oils and soaps for 1938. Oil \& Soap. 1939;16:73-83. Qi F, Kitahara Y, Wang Z, Zhao X, Du W, Liu D. Novel mutant strains of Rhodosporidium toruloides by plasma mutagenesis approach and their tolerance for inhibitors in lignocellulosic hydrolyzate. Journal of Chemical Technology and Biotechnology. 2013.

Radulovic M, Knittelfelder O, Cristobal-Sarramian A, Kolb D, Wolinski H, Kohlwein SD. The emergence of lipid droplets in yeast: current status and experimental approaches. Current genetics. 2013;59:231-42.

Ratledge C. Resources Conservation By Novel Biological Processes. Part 1: Grow fats from wastes. Chem Soc Rev. 1979;8:283-96.

Ratledge C. Yeasts for lipid production. Biochemical Society Transactions. 1988;16:1088. 
Ratledge C. Chapter 22. Biotechnology of oils and fats. In: Ratledge C, Wilkinson S, editors. Microbial Lipids, Volume 2. London: Academic Press, Harcourt Brace Jovanovich; 1989. p. 567-668.

Ratledge C. Single cell oils - have they a biotechnological future? Trends in biotechnology. 1993;11:278-84.

Ratledge C. Regulation of lipid accumulation in oleaginous micro-organisms. Biochemical Society Transaction. 2002;30:1047-50.

Ratledge C. Fatty acid biosynthesis in microorganisms being used for single cell oil production. Biochimie. 2004;86:807-15.

Ratledge C, Cohen Z. Microbial and algal oils: Do they have a future for biodiesel or as commodity oils? Lipid Technol. 2008;20:155-60.

Ratledge C, Wilkinson SG. Microbial lipids: Academic Press London; 1988.

Ratledge C, Wynn J. The biochemistry and molecular biology of lipid accumlation in oleaginous microorganisms. Advances in Applied Microbiology. 2002;51:1-44.

Rattray J. Yeast. In: Ratledge C, Wilkinson S, editors. Microbial lipids. London: Academic Press; 1988. p. 555-697.

Rattray J, Scheibeci A, Kidby D. Lipids of Yeasts. Bacteriological Reviews. 1975;39:197-231. Reichel L. Biologische Fettsynthese. Angewandte Chemie. 1940;53:577-9.

Romaní A, Garrote G, Alonso JL, Parajó JC. Bioethanol production from hydrothermally pretreated Eucalyptus globulus wood. Bioresource Technology. 2010;101:8706-12.

Rossi M, Amaretti A, Raimondi S, Leonardi A. Getting Lipids for Biodiesel Production from Oleaginous Fungi. Biodiesel-feedstocks and processing technologies, InTech, Rijeka. 2011:71-92.

Rossi M, Buzzini P, Cordisco L, Amaretti A, Sala M, Raimondi S, et al. Growth, lipid accumulation, and fatty acid composition in obligate psychrophilic, facultative psychrophilic, and mesophilic yeasts. Microb Ecol. 2009;69:363-72.

Sampaio J. Chapter 127. Rhodosporodium Banno (1967). In: Kurtzman CP, Fell J, Boekhout T, editors. The Yeasts: A Taxonomic Study. Amsterdam: Elsevier; 2011. p. 1523-40.

Sampaio J, Gadanho M, Santos S, Duarte F, Pais C, Fonseca A, et al. Polyphasic taxonomy of the basidiomycetous yeast genus Rhodosporidium kratochvilovae and related anamorphic species. International Journal of Systematic and Evolutionary Microbiology. 2001;51:687-97. Sandager L, Gustavsson MH, Ståhl U, Dahlqvist A, Wiberg E, Banas A, et al. Storage lipid synthesis is non-essential in yeast. Journal of Biological Chemistry. 2002;277:6478-82. Schiller J, Arnhold J, Benard S, Müller M, Reichl S, Arnold K. Lipid Analysis by MatrixAssisted Laser Desorption and Ionization Mass Spectrometry: A Methodological Approach. Analytical Biochemistry. 1999;267:46-56.

Schmidt E. Eiweiß und Fettgewinnung über Hefe aus Sulfitablauge. Angewandte Chemie. 1947;59:16-20.

Schmidt-Dannert C, Holtzapple E. Isoprenoid was ester synthases, isoprenoid acyl CoAsynthetases, and uses thereof. In: USPTO, editor.2009.

Schwalbach M, Keating D, Tremaine M, Marner W, Zhang Y, Bothfeld W, et al. Complex physiology and compound stress responses during fermentation of alkali-pretreated corn stover hydrolysate by an Escherichia coli ethanologen. Applied and Environmental Microbiology. 2012;78:3442-57.

Schweizer M. Lipids and membranes. In: Dickinson J, Schweizer M, editors. The Metabolism and Molecular Physiology of Saccharomyces cerevisiae. Philadelphia, PA: CRC Press; 2004. 
Sentheshanmuganathan S, Nickerson W. Composition of cells and cell walls of triangular and ellipsoidal forms of Trigonopsis variabilis. J Gen Microbiol. 1962;27:451-64.

Sheehan J. A look back at the U.S. Department of Energy's Aquatic Species Program [electronic resource] : biodiesel from algae / by John Sheehan ... [et al.] ; prepared by the National Renewable Energy Laboratory. Golden, Colo: National Renewable Energy Laboratory; 1998.

Shi S, Valle-Rodriguez J, Siewers V, Nielsen J. Prospects for microbial biodiesel production. Biotechol J. 2011;6:277-85.

Sitepu I, Ignatia L, Franz A, Wong D, Faulina S, Tsui M, et al. An improved high-throughput Nile red fluorescence assay for estimating intracellular lipids in a variety of yeast species. Journal of Microbiological Methods. 2012;91:321-8.

Sitepu I, Jin M, Fernandez J, Sousa L, Balan V, Boundy-Mills K. Lipid accumulation by oleaginous yeasts in synthetic and authentic $\operatorname{AFEX}\left({ }^{\mathrm{TM}}\right)$ corn stover hydrolysate. Applied microbiology and biotechnology. 2014a; In press.

Sitepu I, Selby T, Zhu S, Lin T, Boundy-Mills K. Carbon source utilization and inhibitor tolerance of 45 oleaginous yeast species. Journal of Industrial Microbiology and Biotechnology. 2014b;41:1061-70.

Sitepu IR, Sestric R, Ignatia L, Levin D, Bruce German J, Gillies LA, et al. Manipulation of culture conditions alters lipid content and fatty acid profiles of a wide variety of known and new oleaginous yeasts species. Bioresource Technology. 2013;144:360-9.

Solazyme. Technology: Biotechnology that creates renewable oils from microalgae. 2013. Spanova M, Zweytick D, Lohner K, Klug L, Leitner E, Hermetter A, et al. Influence of squalene on lipid particle/droplet and membrane organization in the yeast Saccharomyces cerevisiae. Biochimica et Biophysica Acta (BBA)-Molecular and Cell Biology of Lipids. 2012;1821:647-53.

Srere PA. The enzymology of the formation and breakdown of citrate. Advances in Enzymology and Related Areas of Molecular Biology, Volume 43. 1975:57-101.

Stanier R. Some aspects of microbiological research in Germany. BIOS Final Report No 691, Item No 24. London: British Intelligence Objectives Sub-Committee; 1946.

Starkey R. Lipid Production By A Soil Yeast. J Bacteriol. 1946;51:33-50.

Steen E, Kang Y, Bokinsky G, Hu Z, Schirmer A, McClure A, et al. Microbial production of fatty-acid-derived fuels and chemicals from plant biomass. Nature. 2010;463:559-62.

Stodola F, Deinema M, Spencer J. Extracelluar Lipids of Yeast. Bacteriological Reviews. Baltimore: American Society for Microbiology; 1967. p. 194-213.

Sugita T. Trichosporon Behrend (1890). In: Kurtzman CP, Fell J, Boekhout T, editors. The Yeasts: A Taxonomic Study. Amsterdam: Elsevier; 2011. p. 2015-61.

Suutari M, Liukkonen K, Laakso S. Temperature adaptation in yeasts: the role of fatty acids. J Gen Microbiol. 1990;136:1469-74.

Tanimura A, Takashima M, Sugita T, Endoh R, Kikukawa M, Yamaguchi S, et al. Cryptococcus terricola is a promising oleaginous yeast for biodiesel production from starch through consolidated bioprocessing. Scientific reports. 2014a;4.

Tanimura A, Takashima M, Sugita T, Endoh R, Kikukawa M, Yamaguchi S, et al. Selection of oleaginous yeasts with high lipid productivity for practical biodiesel production. Bioresource Technology. 2014b;153:230-5. 
Tao J, Dai C-C, Yang Q-Y, Guan X-Y, Shao W-L. Production of biodiesel with acid hydrolysate of Populus Euramevicana $C V$ [sic] leaves by Rhodotorula glutinis International Journal of Green Energy. 2010;7:387-96.

Tatsumi C, Hashimoto Y, Masahiko T, Matsuo T. Method for producing cacao butter substitute. In: USPOT, editor. US1977.

Thakur M, Prapulla S, Karanth N. Estimation of intracellular lipids by the measurement of absorbance of yeast cells stained with Sudan Black B. Enzyme and microbial technology. 1989;11:252-4.

Thiru M, Sankh S, Rangaswamy V. Process for biodiesel production from Cryptococcus curvatus. Bioresour Technol. 2011;102:10436-40.

Tornqvist E, Lundin H. The Biotechnical Production of Fat Using Cane Molasses as Raw Material. The International Sugar Journal. 1951:123-7.

Trimbur DE, Im C-s, Dillon HF, Day AG, Franklin S, Coragliotti A. Lipid Pathway Modification in Oil-Bearing Microorganisms. US Patent 20,120,288,930; 2012a.

Trimbur DE, Im C-S, Dillon HF, Day AG, Franklin S, Coragliotti A. Renewable Chemicals and Fuels From Oleaginous Yeast. Google Patents; 2012b.

Tsigie YA, Wang C-Y, Truong C-T, Ju Y-H. Lipid production from Yarrowia lipolytica Po1g grown in sugarcane bagasse hydrolysate. Bioresource Technology. 2011;102:9216-22.

Turcotte G, Kosaric N. Biosynthesis of lipids by Rhodosporidium toruloides ATCC 10788. Journal of biotechnology. 1988;8:221-37.

Turcotte G, Kosaric N. Lipid Biosynthesis in Oleaginous Yeasts. Advances in Biochemical Engineering/ Biotechnology. 1989;40:74-92.

US Energy Information Administration. Energy Consumption by Sector. http://www.eia.gov/totalenergy/data/annual/pdf/sec2.pdf. Accessed 26 November 2013. . 2013.

Van Bogaert IN, Zhang J, Soetaert W. Microbial synthesis of sophorolipids. Process Biochemistry. 2011;46:821-33.

Van Dyk J, Pletschke B. A review of lignocellulose bioconversion using enzymatic hydrolysis and synergistic cooperation between enzymes-Factors affecting enzymes, conversion and synergy. Biotechnology Advances. 2012;30:1458-80.

Van Rensburg E, Kock J, Coetzee D, Botha A, Botes P. Lipid composition and band patterns in the yeast family Lipomycetaceae. System Appl Micrbiol. 1995;18:410-24.

Vaughan-Martini A, Martini A. Facts, myths and legends on the prime industrial microorganism. J Ind Microbiol Biotechnol. 1995;14:514-22.

Viljoen B, Knox A, Beuchat L, Deak T, Malfeito-Ferreira M, Hansen T, et al. An interlaboratory evaluation of selective media for the detection and enumeration of yeasts from blueveined cheese. Int J Food Microbiol. 2004;94:9-14.

Viljoen B, Kock J, Lategan P. Long-chain fatty acid composition of selected genera of yeasts belonging to the Endomycetales. Antonie van Leeuwenhoek. 1986;52:45-51.

Volkman JK, Everitt DA, Allen DI. Some analyses of lipid classes in marine organisms, sediments and seawater using thin-layer chromatography-flame ionisation detection. Journal of Chromatography A. 1986;356:147-62.

Vorapreeda T, Thammarongtham C, CHeevadhanarak S, Laoteng K. Alternative routes of acetyl-CoA synthesis identified by comparative genomic analysis: involvement in the lipid production of oleaginous yeast and fungi. Microbiology. 2012;158:217-28. 
Wang Q, Guo F-J, Rong Y-J, Chi Z-M. Lipid production from hydrolysate of cassava starch by Rhodosporidium toruloides 21167 for biodiesel making. Renewable Energy. 2012.

Wang Q-M, Bai F-Y. Molecular phylogeny of basidiomycetous yeasts in the Cryptococcus luteolus lineage (Tremellales) based on nuclear rRNA and mitochondrial cytochrome b gene sequence analyses: proposal of Derxomyces gen. nov. and Hannaella gen. nov., and description of eight novel Derxomyces species. FEMS Yeast Research. 2008;8:799-814. Wassef M. Fungal lipids. Adv Lipids Res. 1977;15:159-232.

Weiss SB, Kennedy EP. The enzymatic synthesis of triglycerides. Journal of the American Chemical Society. 1956;78:3550-.

Weissman J, Radaelli G, Rice D. Systems and methods for maintaining the dominance and increasing the biomass production of Nannochloropsis in an algae cultivation system. Google Patents; 2012.

Wiebe M, Koivuranta K, Penttila M, Ruohonen L. Lipid production in batch and fed-batch cultures of Rhodosporidium toruloides from 5 and 6 carbon carbohydrates. BMC Biotechnology. 2012;12:26.

Willats WG, Knox JP, Mikkelsen JD. Pectin: new insights into an old polymer are starting to gel. Trends in Food Science \& Technology. 2006;17:97-104.

Woodbine M. Microbial Fat: Micro-Organisms as Potential Fat Producers. Progress in Industrial Microbiology1959. p. 179-245.

Wu S, Hu C, Jin G, Zhao X, Zhao Z. Phosphate-limitation mediated lipid production by Rhodosporidium toruloides. Bioresource Technology. 2010;101:6124-9.

Wyman CE. Biomass ethanol: technical progress, opportunities, and commercial challenges. Annual Review of Energy and the Environment. 1999;24:189-226.

Wyman CE, Dale BE, Elander RT, Holtzapple M, Ladisch MR, Lee Y. Coordinated development of leading biomass pretreatment technologies. Bioresource technology. 2005;96:1959-66.

Xie H, Shen H, Gong Z, Wang Q, Zhao Z, Bai F. Enzymatic hydrolysates of corn stover pretreated by a $N$-methylpyrrolidone-ionic liquid solution for microbial lipid production. Green Chemistry. 2012;14:1202-10.

Xiong W, Liu L, Wu C, Yang C, Wu Q. 13C-tracer and gas chromatography-mass spectrometry analyses reveal metabolic flux distribution in the oleaginous microalga Chlorella protothecoides. Plant physiology. 2010;154:1001-11.

Yakes E, Arsenault J, Islam M, Hossain M, Ahmed T, German J, et al. Intakes and breast-milk concentrations of essential fatty acids are low among Bangladeshi women with 24-48-monthold children. British Journal of Nutrition. 2011;105:1660-70.

Yang X, Jin G, Gong Z, Shen H, Song Y, Bai F, et al. Simultaneous utilization of glucose and mannose from spent yesat cell mass for lipid production by Lipomyces starkeyi. Bioresour Technol. 2014;158:383-7.

Yen C, Mack D. Immunoquantitation of hepatic ATP citrate lyase in the starved, sucrose-refed, and fat-refed rat. Nutrition Reports International. 1980;22:245-52.

Yen K, Le TT, Bansal A, Narasimhan SD, Cheng J-X, Tissenbaum HA. A comparative study of fat storage quantitation in nematode Caenorhabditis elegans using label and label-free methods. PLoS ONE. 2010;5:e12810.

Ykema A, Verbree EC, Kater MM, Smit H. Optimization of lipid production in the oleaginous yeastApiotrichum curvatum in wheypermeate. Applied microbiology and biotechnology. 1988;29:211-8. 
Yoon S, Rhee J. Lipid from Yeast Fermentation: Effects of Cultural Conditions. Journal of the American Oil Chemists' Society. 1983;60:1281-6.

Yoon S, Rhim J, Choi S, Ryu D, Rhee J. Effect of Carbon and Nitrogen Sources on Lipid Production of Rhodotorula gracilis. J Ferment Technol. 1982;60:243-6.

Yu X, Zheng Y, Dorgan K, Chen S. Oil production by oleaginous yeasts using the hydrolysate from pretreatment of wheat straw with dilute sulfuric acid. Bioresour Technol. 2011;102:613440.

Zha Y, Muilwijk B, Coulier L, Punt P. Inhibitory compounds in lignocellulosic biomass hydrolysates during hydrolysate fermentation processes. J Bioprocess Biotechniq. 2012;2:11222.

Zhan J, Lin H, Shen Q, Zhou Q, Zhao Y. Potential utilization of waste sweetpotato vines hydrolysate as a new source for single cell oils production by Trichosporon fermentans. Bioresour Technol. 2013;In press.

Zhang J, Zhu Z, Wang X, Wang N, Wang W, Bao J. Biodetoxification of toxins generated from lignocellulose pretreatment using a newly isolated fungus, Amorphotheca resinae $\mathrm{ZN1}$, and the consequent ethanol fermentation. Biotechnology for Biofuels. 2010;3:1-15.

Zhao X, Kong X, Hua Y, Feng N, Zhao Z. Medium optimization for lipid production through co-fermentation of glucose and xylose by the oleaginous yeast Lipomyces starkeyi. Eur J Lipid Sci Technol. 2008;110:405-12.

Zhelifonova V, Krylova N, Dedyukhina E, Eroshin V. Investigation on lipid-forming yeasts growing on a medium with ethanol. Mikrobiologiya. 1983;52:219-24.

Zhu L, Zong M, Wu H. Efficient lipid production with Trichosporon fermentans and its use for biodiesel preparation. Bioresour Technol. 2008;99:7881-5.

Zhu Z, Zhang S, Liu H, Shen H, Lin X, Yang F, et al. A multi-omic map of the lipid-producing yeast Rhodosporidium toruloides. Nature communications. 2012;3:1112.

Zotova E, Gavrilova N, Nechaev A. The influence of cultivation conditions on the lipid composition of Candida humicola 2043. Prikladnaia Biokhimiia i Mikrobiologiia. 1985;21:634-9. 

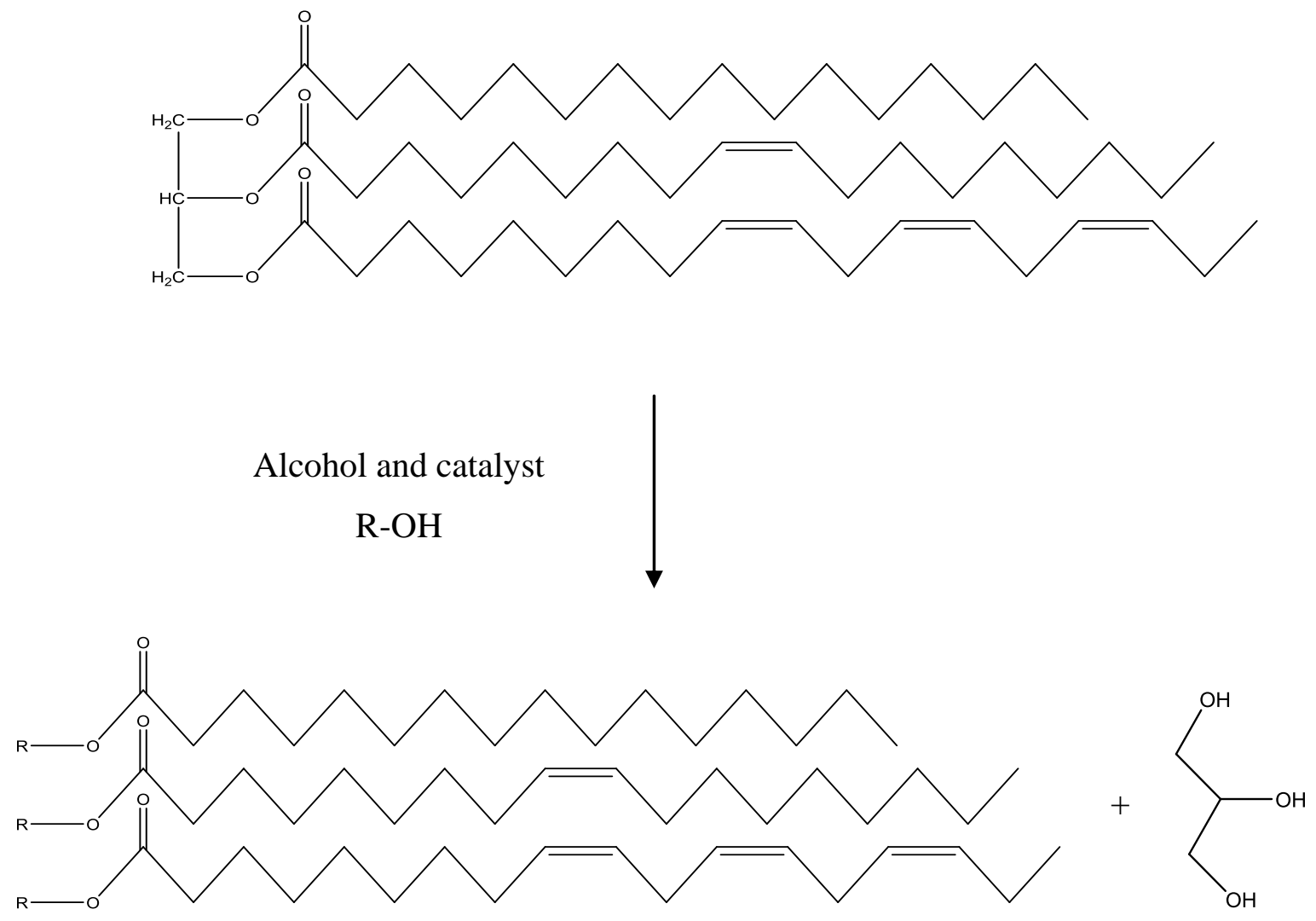


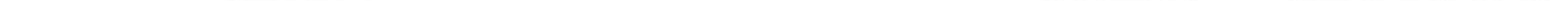




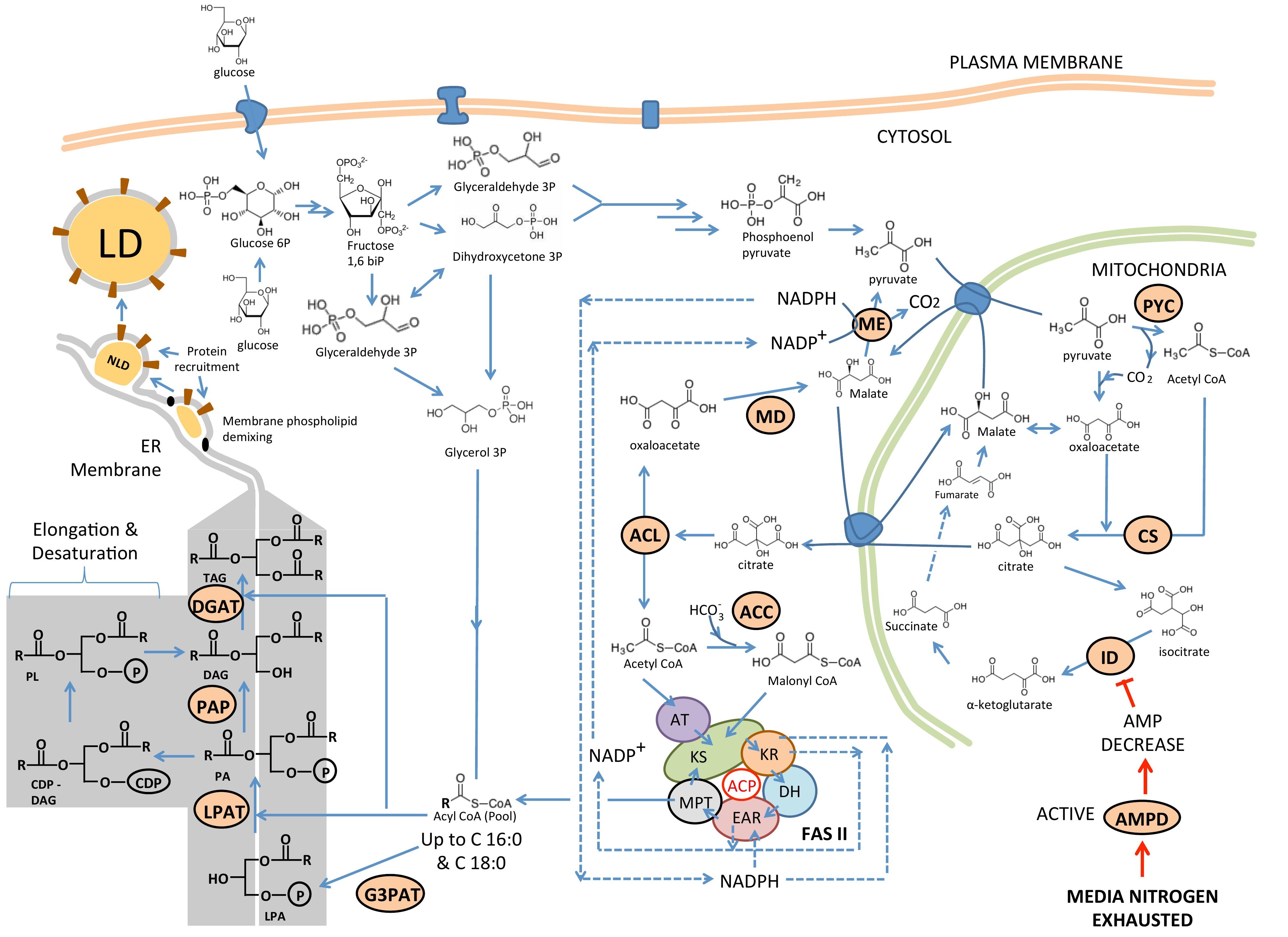

